\title{
What Drives the Performance of Convertible-Bond Funds?
}

\author{
Manuel Ammann, Axel Kind, and Ralf Seiz*
}

July 2007

\begin{abstract}
This paper examines the performance of US mutual funds investing primarily in convertible bonds. Although convertible-bond funds are popular investment vehicles, their return process is not well understood. We contribute an analysis of the complete universe of US convertible-bond funds proposing a set of multi-factor models for the return generating process. In spite of the well-known hybrid nature of convertible bonds, the return process of convertible-bond funds cannot be fully explained by factors typically related to stock and bond markets. Thus, we consider additional variables accounting for the option-like character of convertible bonds. Surprisingly, multivariate cross-sectional analyses show the existence of a significant positive relationship between a fund's performance and its asset composition. Similar to Agarwal et al. (2006) we show that this result can be explained by factors related to investment opportunities in the convertiblebond market and trading strategies related to convertible arbitrage, as typically performed by hedge funds. Overall, convertible-bond funds have a performance as measured by alpha that is comparable to passive investment strategies in stocks, bonds, and convertible bonds. This average performance is the result of weak selection skills and successful timing of strategies related to convertible arbitrage.
\end{abstract}

Keywords: Mutual Funds, Performance, Hybrid Securities, Convertible Bonds. JEL classification: G12, G13, G15.

\footnotetext{
* Manuel Ammann, Axel Kind, and Ralf Seiz are at the Swiss Institute of Banking and Finance, University of St. Gallen, Rosenbergstrasse 52, 9000 St.Gallen, Switzerland. Tel: +4171-224-7090, Fax +4171-224-7088, Email: manuel.ammann@unisg.ch, axel.kind@unisg.ch, ralf.seiz@unisg.ch. Financial support by the Swiss National Science Foundation (SNF) and the Research Fund of the University of St. Gallen (GFF) is gratefully acknowledged. We thank Yakov Amihud, Edwin Elton, Stephen Figlewski, Georg Hübner, Christian Koziol, Lorne Switzer, Michael Steiner, and participants at the 2006 Northern Finance Association Meeting in Montreal, the 2006 German Finance Association Meeting in Oestrich-Winkel, the 2006 Topics in Finance Seminar in St. Moritz, the 2007 Swiss Finance Association Meeting in Zurich, the 2007 Eastern Finance Association Meeting in New Orleans, the 2007 European Financial Management Association Meeting in Vienna, and the 2007 European Conference on Operational Research in Prague for their very helpful comments.
} 


\section{Introduction}

With an estimated global market volume of more than 40 billion US dollars in $2005,{ }^{1}$ convertible-bond funds (CBFs) are an important constituent of the investment universe. A convertible bond gives the holder the right to exchange (convert) a bond for a certain number of shares of the bond-issuing company. Simplistically, it can be viewed as a combination of a straight bond and a call option on the equity of the issuing firm. Besides combining attributes of fixed-income securities and equities, convertible bonds present their own return characteristics related to the option-like nature of the instruments. For this reason, convertible bonds are often seen by professionals in the asset management industry as a distinct asset class ${ }^{2}$. Interestingly, while both academics and practitioners have extensively studied the performance and return characteristics of individual stocks, bonds, equity funds, and bond funds, ${ }^{3}$ little attention has been dedicated to studying and explaining the performance of funds investing in convertible bonds. From a theoretical perspective, as convertible-bond funds invest in derivative instruments, a model explaining returns has to account for non-linear payoffs and dynamic strategies. In this context, it is a relevant question whether in addition to stock and bond factors, there exist factors specific to convertible-bond funds. This issue has important implications for risk management, portfolio optimization, and performance measurement. From a practical perspective,

\footnotetext{
${ }^{1}$ Estimation is based on data provided by Lipper Global Fund Screener, CRSP, and Datastream.

${ }^{2}$ The reader may refer to Lummer and Riepe (1993) for one of the first studies taking the view that convertible bonds represent a distinct asset class.

${ }^{3}$ For the return characteristics of common stocks, see Chen, Roll and Ross (1986), Fama and French (1992, 1993), Carhart (1997), Burmeister and Wall (1986), Elton, Gruber and Blake (1999), Ferson and Schadt (1996), among others. For bonds, see Elton, Gruber and Blake (1999). For both asset classes, see Fama and French (1993).
} 
investors are interested to know whether CBFs provide downside protection due to the so called bond-floor of convertible bonds, and more generally, if they deliver an attractive risk-return trade-off.

This paper contributes the first empirical study of the US CBF market. It investigates the complete (survivorship-bias free) universe of convertible-bond funds in the US consisting of 114 CBFs in the period of 1985-2004. We provide a detailed description of US convertible-bond funds and propose a set of models which include factors typically related to stocks and bonds as well as factors capturing the option-like character of convertible bonds. The results we obtain can be summarized as follows. First, CBF returns are to a large extent normally distributed and do not provide a substantial protection against adverse movements in the stock market. Second, common factors for stocks, bonds, and convertible bonds are not sufficient to explain the cross-sectional variation in CBF returns. More precisely, cross-sectional abnormal returns are found to be significantly positively (negatively) related to the fund's convertible bond (equity) holdings. We argue that CBFs most likely pursue dynamic trading strategies related to the long side of convertible arbitrage. Selected funds may even perform full-fledged convertible-arbitrage strategies as they are entitled to short stocks (long-short funds). Third, CBF returns display significant timing skills. They are found to successfully time the convertible-bond and convertiblearbitrage market, but not the stock market. In particular, CBFs seem to increase their convertible-arbitrage related activities in phases when this strategy performs well, i.e., when the supply of convertible bonds is large and investment opportunities in the convertible-bond market are favorable. Finally, this successful timing activity offsets both 
the negative impact of management fees and the weak selection skills of CBF portfolio managers in the stock, bond, and convertible-bond market.

The structure of the paper is as follows: Section 2 describes the CBF market and the data set used in the article. Section 3 describes the factors that, based on economic rationales, are likely to drive the performance of CBFs. Section 4 proposes and tests a large set of factor models. Section 5 extends the analysis to factors related to dynamic trading strategies, such as convertible arbitrage and timing activities. Section 6 discusses the performance of CBFs by focusing on alphas. Section 7 concludes. 


\section{U.S. Convertible-Bond Funds}

In this paper, we investigate the U.S. market for convertible-bond funds (CBFs) between October 1985 and December 2004. According to the CRSP (Center for Research in Security Prices) $)^{4}$ survivorship-free database, $129 \mathrm{CBFs}$ are traded in this period, out of which 14 are closed-end funds. In the same time, $41 \mathrm{CBFs}$ were terminated, resulting in 73 active open-end CBFs with a market volume of 10.6 billion US dollars as of December 2004. As depicted in Table I, the final sample of CBFs analyzed in this study includes 114 open-end convertible-bond funds.

Interestingly, CBFs do not exclusively invest in convertible securities, such as convertible bonds (38\% average holding) and preferred stocks (20\%), but also in stocks (11\%) and bonds (13\%). Further, some of the funds are so called long-short CBFs, which are allowed to have short positions in stocks but are nevertheless part of the mutual fund universe defined by the 1940 Investment Advisory Act. Convertible-bond funds have on average total net assets of $\$ 120$ million, new money growth of $2 \%$ per month, and expense ratios of $1.5 \%$, which is between the expense ratios commonly charged by bond funds and stock funds (cf. Table II).

\footnotetext{
${ }^{4}$ The CRSP database includes information on fund objectives, fund returns, total net asset values, expense ratios, age of the funds, status of the fund (dead or active), asset compositions (e.g. percentages invested in convertible bonds, stocks and bonds), and other fund characteristics. Returns and total net assets are reported monthly, fund characteristics such as asset compositions and expense ratios are generally reported on a yearly basis.
} 
Table I

US Convertible Bond Fund Selection and Yearly Statistics

The data set has been created by the CRSP Survivorship Bias Free US Mutual Fund Database. Panel A describes the fund selection process. The original CRSP sample in the period between 1985 and 2004 contained 129 US convertible-bond funds. We eliminated 14 closed-end funds and a fund with no return data. With these exclusions, our final sample includes 114 convertible-bond funds (73 active convertible-bond funds and 41 dead funds). Our final sample spans the period between October 1985 and December 2004. Panel B gives an overview of the number of active funds and total net assets in each year of the sample in the period between October 1985 and December 2004.

Panel A: Selection of funds of the

CRSP Survivor-Bias Free US Mutual Fund Database: 1985-2004

\begin{tabular}{lc}
\hline Total number of US convertible bond funds in CRSP database & 129 \\
Closed US convertible bond funds in CRSP database & 14 \\
US convertible bond funds with no Return Data in CRSP database & 1 \\
\hline Number of selected active funds (current status) & 73 \\
Number of selected dead funds (current status) & 41 \\
Total number of funds in this study & 114 \\
\hline
\end{tabular}

Panel B: Summary of active funds: 1985-2004

\begin{tabular}{ccc}
\hline & $\begin{array}{c}\text { Number of active } \\
\text { convertible bond funds } \\
\text { (end of year) }\end{array}$ & $\begin{array}{c}\text { TNA } \\
\text { (end of year) } \\
\text { (in \$millions) }\end{array}$ \\
\hline 1985 & 7 & 804 \\
1986 & 12 & 1600 \\
1987 & 16 & 3334 \\
1988 & 23 & 2847 \\
1989 & 23 & 2503 \\
1990 & 22 & 1662 \\
1991 & 19 & 1725 \\
1992 & 23 & 2666 \\
1993 & 25 & 3673 \\
1994 & 28 & 3364 \\
1995 & 35 & 3820 \\
1996 & 38 & 4477 \\
1997 & 46 & 5729 \\
1998 & 45 & 5644 \\
1999 & 47 & 6312 \\
2000 & 52 & 6768 \\
2001 & 60 & 5940 \\
2002 & 60 & 5246 \\
2003 & & 9319 \\
2004 & & 10628 \\
\hline
\end{tabular}




\section{Table II \\ Convertible Bond Fund Summary Statistics}

This table reports summary statistics of the convertible-bond funds of the CRSP (Center for Research in Security Prices) Survivor-Bias Free US Mutual Fund Database investigated in this study. The table shows attributes of 114 US convertiblebond funds from 1985-2004. The mean is the cross-sectional average of time-series averages attributes. The stdev of mean is the cross-sectional standard deviation of the mean. Min and Max are the time-series and cross-sectional minimum and maximum. Panel A shows the main convertible bond fund characteristics and Panel B shows the asset composition of the funds. TNA is total net asset value; NMG (New Money Growth) is the percentage change in TNA adjusted for investment return. EXP is the expenses ratio. TNA are reported monthly, whereas the asset compositions are generally reported yearly (or even more often).

\begin{tabular}{|c|c|c|c|c|}
\hline & Mean & $\begin{array}{c}\text { Stdev of } \\
\text { mean }\end{array}$ & Min & Max \\
\hline \multicolumn{5}{|c|}{ Panel A: Main Convertible Bond Fund Characteristics } \\
\hline Avg TNA (\$ millions) & 120.0 & 255.4 & 0.001 & 2507 \\
\hline Avg New Money Growth (NMG) (in \% per month) & $2 \%$ & $21 \%$ & $-513 \%$ & $550 \%$ \\
\hline Avg Expense Ratio (EXP) (\% per year) & $1.5 \%$ & $0.6 \%$ & $0.01 \%$ & $3.8 \%$ \\
\hline Avg Age (in years) & 7.3 & 7.3 & 0.1 & 48.9 \\
\hline \multicolumn{5}{|c|}{ Panel B: Main Asset Composition of Convertible Bond Funds } \\
\hline Avg \% in Stocks (S) & $11 \%$ & $17 \%$ & $-68 \%$ & $124 \%$ \\
\hline Avg \% in Bonds (incl. Convertibles) (B) & $51 \%$ & $25 \%$ & $0 \%$ & $123 \%$ \\
\hline Avg \% in Convertible Bonds (CB) & $38 \%$ & $28 \%$ & $0 \%$ & $98 \%$ \\
\hline Avg \% in Convertibles - \% in Stocks (CB-S) & $27 \%$ & $34 \%$ & $-96 \%$ & $129 \%$ \\
\hline Avg \% in Bonds (incl. Convertibles) - \% in Stocks (B-S) & $47 \%$ & $27 \%$ & $-96 \%$ & $191 \%$ \\
\hline Avg \% in Preferred Stocks & $20 \%$ & $10 \%$ & $0 \%$ & $82 \%$ \\
\hline Avg $\%$ in Cash & $6 \%$ & $10 \%$ & $-2 \%$ & $100 \%$ \\
\hline
\end{tabular}


Before addressing the performance of CBFs by asset pricing models, we look at some simple, model-free performance measures of CBFs and compare them to benchmarks. Table III presents a comparison of realized returns, volatilities, Sharpe ratios, and Sortino ratios for broad stock, bond, convertible-bond, and convertible-arbitrage indices. Several observations can be made. First, for all periods considered, returns and volatilities of CBFs are between the corresponding values for stocks and bonds. This is not surprising, given the hybrid nature of convertible bonds. Second, the Sharpe ratios of an equally-weighted portfolio of CBFs are always below the stock and straight-bond counterparts, which is indicative of a poor risk-return ratio. Third, the Sortino ratios, which only consider negative returns (below $0 \%$ ) when measuring risk, seem to confirm the poor performance of CBFs. This stands in contrast to the common view that convertible bonds offer a downside protection through the so-called bond floor, the bond-value component of the convertible. However, a Jarque-Bera test statistics supports the results above, because 59\% of the convertible-bond funds in our sample show normally distributed returns. 


\section{Table III}

\section{Convertible Bond Fund Performance}

This table reports summary statistics of the convertible-bond funds of the CRSP (Center for Research in Security Prices) Survivor-Bias Free US Mutual Fund Database investigated in this study (CB Funds). The table shows the performance of 114 US convertible-bond funds from 1985-2004. (CB Funds) are the equally weighted returns in the CRSP convertible bond fund sample. (Stocks) is the value-weighted return on all NYSE, AMEX, and NASDAQ stocks (from CRSP). (Bonds) is the return on the Lehman US aggregated Government/Credit Bond Index. (Convertible Bonds) is the return on the Merrill Lynch All US Convertible Bond Index. (Convertible Arbitrage HF) is the return on the CSFB/Tremont Convertible Arbitrage Hedge Fund Index. The Sharpe ratio is calculated by using a one-month Treasury bill rate (from Ibbotson Associates) and the threshold for calculating the Sortino ratio (Downside Volatility) is set to $0 \%$.

\begin{tabular}{|c|c|c|c|c|c|}
\hline & CB Funds & Stocks & Bonds & $\begin{array}{c}\text { Convertible } \\
\text { Bonds }\end{array}$ & $\begin{array}{l}\text { Convertible } \\
\text { Arbitrage HF }\end{array}$ \\
\hline \multicolumn{6}{|c|}{ Panel A: 10/1985 - 12/2004 } \\
\hline Return (p.a.) & $9.4 \%$ & $13.1 \%$ & $8.2 \%$ & & \\
\hline Volatility (p.a.) & $10.8 \%$ & $15.7 \%$ & $4.8 \%$ & & \\
\hline Downside-Volatility (p.a.) & $12.7 \%$ & $17.9 \%$ & $4.6 \%$ & & \\
\hline Sharpe Ratio & 0.44 & 0.54 & 0.73 & & \\
\hline Sortino Ratio & 0.38 & 0.47 & 0.77 & & \\
\hline \multicolumn{6}{|c|}{ Panel B: 1/1988 - 12/2004 } \\
\hline Return (p.a.) & $9.5 \%$ & $12.6 \%$ & $7.8 \%$ & $10.6 \%$ & \\
\hline Volatility (p.a.) & $10.2 \%$ & $14.5 \%$ & $4.6 \%$ & $11.3 \%$ & \\
\hline Downside-Volatility (p.a.) & $11.0 \%$ & $15.6 \%$ & $4.5 \%$ & $12.3 \%$ & \\
\hline Sharpe Ratio & 0.49 & 0.56 & 0.73 & 0.55 & \\
\hline Sortino Ratio & 0.46 & 0.52 & 0.75 & 0.50 & \\
\hline \multicolumn{6}{|c|}{ Panel C: 1/1994 - 12/2004 } \\
\hline Return (p.a.) & $8.6 \%$ & $11.5 \%$ & $6.5 \%$ & $9.0 \%$ & $9.4 \%$ \\
\hline Volatility (p.a.) & $11.3 \%$ & $15.7 \%$ & $4.6 \%$ & $12.5 \%$ & $4.7 \%$ \\
\hline Downside-Volatility (p.a.) & $12.1 \%$ & $17.6 \%$ & $4.8 \%$ & $13.3 \%$ & $6.3 \%$ \\
\hline Sharpe Ratio & 0.42 & 0.49 & 0.59 & 0.42 & 1.19 \\
\hline Sortino Ratio & 0.40 & 0.43 & 0.56 & 0.39 & 0.88 \\
\hline
\end{tabular}

The threshold for the Downside-Volatility and the Sortino ratio is set to $0 \%$. 


\section{What Factors Drive the Performance of Convertible-Bond Funds?}

In this section, we examine factors that are possibly qualified to explain CBF returns. Overall, we classify risk factors into four categories: (i) stock factors, (ii) bond factors, (iii) option factors, and (iv) fund factors.

\subsection{Stock Factors}

CBFs are likely to be influenced by stock factors because they invest directly in equities and because the price of convertible securities is intrinsically related to the underlying stock. In line with the standard four-factor model proposed by Carhart (1997), we consider the following risk factors: (i) MARKET, is the value-weighted return on all NYSE, AMEX, and NASDAQ stocks minus the one-month Treasury bill rate; (ii) SMB is the return difference between small and large-capitalization stocks; (iii) HML is the difference between high and low book-to-market stocks; and (iv) UMD is the return difference between stocks with high and low past returns.

\subsection{Bond Factors}

Similarly, CBFs are likely to be influenced by bond factors because they invest directly in straight bonds and cash instruments and because convertible securities have a bond component. Following Fama and French (1993), Burmeister and Wall (1986), and Blake, Elton and Gruber (1999), we consider the following four bond risk factors: (i) TERM is a proxy for the unexpected changes in interest rates and is defined as the return of the Lehman US Government Long Bond Index minus the one-month Treasury bill rate; (ii) DEFT is a proxy for the default factor and is defined as the return on the Lehman US 
Corporate Long Bond Index minus the return of the Lehman US Government Long Bond Index ${ }^{5}$; (iii) HY captures both a term and a credit premium and is defined as the return on the Merrill Lynch US High Yield Index. ${ }^{6}$; Finally, (iv) BOND is the excess return of a broad bond index (Lehman US aggregated Government/Credit Bond Index).

\subsection{Option Factors}

The option embedded in convertible bonds to exchange them into shares of the underlying stock resembles a call option. For this reason, it seems plausible that CBF returns may display a dependence on factors affecting option prices. According to standard option pricing theory, the value of non-linear derivatives depends on the volatility of the underlying. Further, a multitude of articles in the field of financial econometrics documents the fact that volatility of single securities and the aggregate market changes over time. For those two reasons, we expect implied volatility on the aggregate market to capture the variation of CBF returns. Motivated by the methods of Henriksson and Merton (1981) and Treynor and Mazuy (1966), we examine non-linear payoff factors and test whether they are significant. Additionally, similar to Agarwal and Naik (2004), we extend the analysis of non-linear factors for convertible bond fund returns to option-based factors consisting of liquid at-the-money (ATM) and out-of-the-money (OTM) European call and put options on the S\&P 500 index trading on the Chicago Mercantile Exchange. The process of generating the call and put time series works as follows: On the first trading day in January, buy an ATM (OTM) call or put option on the S\&P 500 index that expires in

\footnotetext{
${ }^{5}$ The definitions of the term structure factor (TERM) and the default factor (DEFT) are similar to the study of Fama and French (1993).

${ }^{6}$ The use of a high yield index (HY) is similar to the study of Elton, Gruber and Blake (1999)
} 
February. ${ }^{7}$ On the first trading day in February, sell the option bought a month ago and buy another ATM (OTM) call or put option on the S\&P 500 index that expires in March. Repeating this trading pattern every month provides the time series of returns. We select the ATM option as the one whose present value of the strike price is closest to the current index value. We select the OTM put option to be the one with the next lower strike price. Using price data from OptionMetrics, we compute monthly returns to these option-based risk factors for the period of January 1996 to December 2004. By using a convertible-bond index, we intend to capture all residual pricing-relevant influences on convertible bonds funds.

Summing up, we analyze six possible factors: (i) VOLA is the return on the CBOE Volatility VXO Index; (ii) $\max (0$, MARKET-BOND) is the maximum of zero and the value-weighted return on all NYSE, AMEX, and NASDAQ stocks minus the return on the Lehman US aggregated Government/Credit Bond Index; (iii) (MARKET) ${ }^{2}$ is the squared value-weighted return on all NYSE, AMEX, and NASDAQ stocks minus the one-month Treasury bill rate; (iv) ATM is the return on a dynamic portfolio of at-the-money call and put options; (v) OTM is the return on a dynamic portfolio of out-of-the-money call and put options; and (vi) CBI is the return on the Merrill Lynch All US Convertible Bond Index.

\subsection{Fund Factors}

The last category of risk factors arises from specific trading strategies carried out by CBF fund managers. In particular, we are interested in capturing variations of convertible-bond-

\footnotetext{
${ }^{7}$ The time to maturity of the options is between one and two months when the options are bought. The results remain similar when the time to maturity is between two and three months when the options are bought.
} 
fund returns arising from convertible arbitrage or related convertible-picking strategies (the long part of a typical long short convertible arbitrage strategy). For this purpose, we choose the returns on the CSFB/Tremont Convertible Arbitrage Index, CBAI. Additionally, Agarwal et al. (2006) argue that convertible-arbitrage hedge funds play an important role in supplying liquidity to the convertible-bond market. They argue that convertiblearbitrage hedge funds behave like liquidity providers to the convertible-bond market and demonstrate the importance of supply-demand effects in determining the returns of hedge fund strategies. Thus, similar to Agarwal et al. (2006), we estimate the net supply of convertible bonds by aggregating every month the market capitalization of convertible bonds traded in the US and subtracting the assets under management in US convertiblebond funds ${ }^{8}$. We approximate the demand for convertible bonds by aggregating the total AuM of all convertible arbitrage hedge funds in the TASS database at the end of each month. The ratio of net supply and demand, SD, can be considered as the investment opportunities available in the convertible bond market. Agarwal et al. (2006) show that after accounting for the investment opportunities, convertible arbitrage hedge funds no longer deliver abnormal returns. They further show that the risk-adjusted returns of convertible arbitrage hedge funds are affected by the investment opportunities (supply and demand) in the convertible bond market.

\footnotetext{
${ }^{8}$ We use the "UBS US Convertible Bond Index" as a proxy for the market capitalization of US convertible bonds and the AuM data for the convertible-bond funds is from the CRSP mutual fund database.
} 


\section{Empirical Analysis of the Performance Drivers}

In this section, we examine factor-based performance models for CBFs. In a first step, we address the question of the time-variation of factor loadings and describe the class of performance models to be used in this study. In a second step, we set up specific models that combine factors typically related to stocks and bonds. This choice of risk factors has two main rationales: First, convertible bonds can be viewed as hybrid securities combining both stock and bond pricing features. Second, as seen in the previous section, while convertible-bond funds mainly focus on convertible bonds, they also invest substantial parts of their portfolios in common stocks and straight bonds. In a third step, we analyze if there are additional systematic factors, possibly related to the option-like character of convertible bonds, that have further explanatory power.

\subsection{Model}

Usually, asset pricing models linearly relate excess returns to a set of risk factors in the following way: ${ }^{9}$

$$
\mathrm{R}_{\mathrm{i}, \mathrm{t}}-\mathrm{R}_{\mathrm{F}, \mathrm{t}}=\alpha_{\mathrm{i}}+\Sigma_{\mathrm{k}} \beta_{\mathrm{i}}^{\mathrm{k}} \cdot \mathrm{F}_{\mathrm{t}}^{\mathrm{k}}+\mathrm{e}_{\mathrm{i}, \mathrm{t}}
$$

where $R_{i, t}-R_{F, t}$ are excess returns of security $i$ over the risk free rate from time $t-1$ to time $\mathrm{t}, \mathrm{F}_{\mathrm{t}}^{\mathrm{k}}$ are the explanatory factors in the performance model, $\beta_{\mathrm{i}}^{\mathrm{k}}$ are the constant factor

\footnotetext{
${ }^{9}$ See, for example, Fama and French (1993), Carhart (1997), or Elton, Gruber, and Blake (1999), among others.
} 
loadings, $\alpha_{i}$ are the measures of the abnormal performance, and $e_{i, t}$ are independent normally distributed errors. In our paper, $\mathrm{R}_{\mathrm{i}, \mathrm{t}}-\mathrm{R}_{\mathrm{F}, \mathrm{t}}$ refers the monthly excess-returns of convertible bond fund $\mathrm{i}$ and will be denoted FUND $\mathrm{i}_{\mathrm{t},}$. While such model specifications are still widely used, a number of authors have questioned the assumption of constant factor loadings, $\beta^{\mathrm{k}}{ }_{\mathrm{i}}$. For instance, Ferson and Schadt (1996), Jagannathan and Wang (1996), Berk, Green, and Naik (1999), Lettau and Ludwigson (2001), and more recently Santos and Veronesi (2004) and Ang and Chen (2005) among others have proposed models with timevarying betas. These authors suggest several economic reasons that might cause time variability, such as the business cycle, changes in financial leverage, technology shocks, or, in the case of mutual fund returns, the trading behavior of managers. Interestingly, convertible bonds have an even more fundamental reason for displaying time-variability of betas: Their sensitivity towards market movements can range from zero, as in the case of a deep out-of-the money convertible, to values even larger than one, for deep in-the-money convertibles issued by high-beta firms.

A simple example shall illustrate the time-variability of convertible-bond betas, which we refer to as the delta effect of convertibles. We consider stocks, straight bonds, and convertible bonds in an economy with constant interest rates. Stock returns are assumed to follow a data generating process in accordance to the CAPM:

$$
\mathrm{R}_{\mathrm{i}, \mathrm{t}}=\mathrm{R}_{\mathrm{F}, \mathrm{t}}+\beta_{\mathrm{i}} \cdot\left(\mathrm{R}_{\mathrm{M}, \mathrm{t}}-\mathrm{R}_{\mathrm{F}, \mathrm{t}}\right)+\mathrm{e}_{\mathrm{i}, \mathrm{t}} \text {, with } \mathrm{e}_{\mathrm{i}} \sim \mathrm{N}\left(0, \sigma_{\mathrm{i}}\right) \text { i.i.d. }
$$

The return of the aggregate stock market is equal to a constant market price of risk (MPR) plus a normally distributed shock: 


$$
\mathrm{R}_{\mathrm{M}, \mathrm{t}}=\mathrm{MRP}+\mathrm{e}_{\mathrm{M}, \mathrm{t}} \text {, with } \mathrm{e}_{\mathrm{M}} \sim \mathrm{N}\left(0, \sigma_{\mathrm{M}}\right) \text { i.i.d. }
$$

If we assume that the convertible bond is not exchangeable into the stock prior to maturity, it can be considered as a combination of a straight bond plus a call option. ${ }^{10}$ Thus the market sensitivity of the convertible bond towards the market, $\beta_{\text {conv }}$, can be expressed as:

$$
\beta_{\text {conv }}=\frac{\partial R_{\text {conv }}}{\partial R_{M}}=\frac{\partial R_{\text {conv }}}{\partial R_{\text {equity }}} \cdot \frac{\partial R_{\text {equity }}}{\partial R_{M}}=\Delta_{\text {conv }} \cdot P_{\text {equity }} / P_{\text {conv }} \cdot \beta_{\text {equity }}
$$

where $R_{\text {conv }}, R_{M}$ and $R_{\text {equity }}$ are returns of the convertible bond, the market portfolio, and the stock of the company; $\mathrm{P}_{\text {equity }}$ and $\mathrm{P}_{\text {call }}$ are the prices of the equity and the convertible bond, and $\Delta_{\text {call }}$ is the delta of the convertible bond, which is, in this particular example, equivalent to the delta of a standard call option. Since the delta of an option changes over time, also the beta of a convertible bond, i.e. its sensitivity towards the market, will change over time. Thus, employing a constant beta model, such as the one in Equation (2), for estimating the "true" beta of a convertible bond, can generate inaccurate results.

The finance literature has proposed several approaches to deal with the issue of timevarying betas: (i) rolling regressions (e.g. Sirri and Tufano, 1992), (ii) instrumental variables (e.g. Ferson and Schadt, 1996), and (iii) latent variables (e.g. Ang and Chen,

\footnotetext{
${ }^{10}$ For the sake of simplicity, we assume that the issuing company has no credit risk, the convertible bond has no callability, no putability, and it is only exercisable at maturity (European-style convertibility). While such characteristic are usually not given in practice, relaxing them increases the complexity of the pricing task but does not qualitatively alter the results of this example.
} 
2005). In this paper, we address the issue by employing rolling regressions and models with latent variables, which we estimate using Kalman filtering: ${ }^{11}$

$$
\begin{gathered}
\mathrm{R}_{\mathrm{i}, \mathrm{t}}-\mathrm{R}_{\mathrm{F}, \mathrm{t}}=\alpha_{\mathrm{i}, \mathrm{t}}+\beta_{\mathrm{i}, \mathrm{t}}\left(\mathrm{R}_{\mathrm{M}, \mathrm{t}}-\mathrm{R}_{\mathrm{F}, \mathrm{t}}\right)+\sum_{\mathrm{k}} \beta_{\mathrm{i}}^{\mathrm{k}} \mathrm{F}_{\mathrm{t}}^{\mathrm{k}}+\mathrm{e}_{\mathrm{i}, \mathrm{t}} \text {, with } \mathrm{e}_{\mathrm{i}} \sim \mathrm{N}\left(0, \sigma_{\mathrm{i}}\right) \text {, and } \\
\beta_{\mathrm{i}, \mathrm{t}}=\beta_{0}+\varphi \beta_{\mathrm{i}, \mathrm{t}-1}+\eta_{\mathrm{i}, \mathrm{t}}, \text { with } \eta_{\mathrm{i}, \mathrm{t}} \sim \mathrm{N}\left(0, \sigma_{\beta \mathrm{i}}\right),
\end{gathered}
$$

where the first equation is the measurement equation and the second one is the state equation of the latent factor loading (beta). While several factors could potentially display time-varying loadings, we choose to restrict ourselves to one latent factor, arguably the market factor, in order to work with reasonably parsimonious models.

Figure 1, Panel A shows the evolution over time of the convertible bond beta, $\beta_{\text {conv, }}$ (solid line) for one simulated path. The standard linear factor model cannot capture this pattern but estimates instead a constant beta, which can be interpreted as an average of the true time-varying beta. For the displayed path, the root-mean squared error of beta amounts to 0.21 . By employing rolling regressions, an important portion of the variation of $\beta_{\text {conv }}$ can be captured (dotted line) and the RMSE of betas can be reduced to 0.17 . However, the initial window of data is lost and the estimated beta lags behind the true beta. Overall, the best fit is obtained with the latent model (dashed line) with a RMSE of 0.09.

\footnotetext{
${ }^{11}$ The recent literature favours the use of latent variables (see Ang and Chen, 2005). Rolling regressions provide an approximation of time-varying betas which is rather ad hoc. On the other hand, as noted by Harvey (2001), the choice of instruments in modelling time-varying betas is to a large extent arbitrary and results may vary widely depending on the instruments used.
} 


\section{Figure 1}

\section{Actual and Estimated Loadings of Convertible-Bond Funds}

This figure shows the development over a period of ten years (simulated with monthly frequency) of the market beta of a convertible bond fund (solid lines). Panel A refers to a fund that consists simply of one convertible bond. Panel B, refers to a fund that invests two convertible bonds (each with a $25 \%$ weight), the two underlying stocks (each with a weight of $12.5 \%$ ), and a riskles zero-beta bond $(25 \%)$. All convertible bonds are non-callable and non-putable. They have a maturity of ten years and can be converted by the investor solely at maturity (European-style convertibles). The theoretical beta is displayed as solid black line. According to Equation (2), the theoretical beta corresponds of three multiplicative components: the equity beta, the delta of a call option with a strike price equal to the notional of the convertible bond and written on the stock of the issuing firm, and the ratio of stock price to convertible bond price. Further, three commonly used estimation models are applied to estimate beta by solely using observed fund returns and market returns: (i) a simple OLS regression with constant beta (dashed horizontal line), (ii) a rolling OLS regression with a 36-month window (dotted line), and (iii) a model with a time-varying latent betas estimated by Kalman filtering (dashed line). The following assumptions underlie this example. The returns of the underlying stocks linearly depends on the market return (CAPM assumption). The underlying stocks have an annualized idiosyncratic volatility of $10 \%$ and betas of 1.5 (Panel A), 1.1, and 0.9 (Panel B). Market returns are independent and normally distributed with an annual drift of $8 \%$ and standard deviation of $15 \%$. The random draws for the market and one stock are held constant in both graphs.

\section{Panel A: Straight Convertible-Bond Fund}

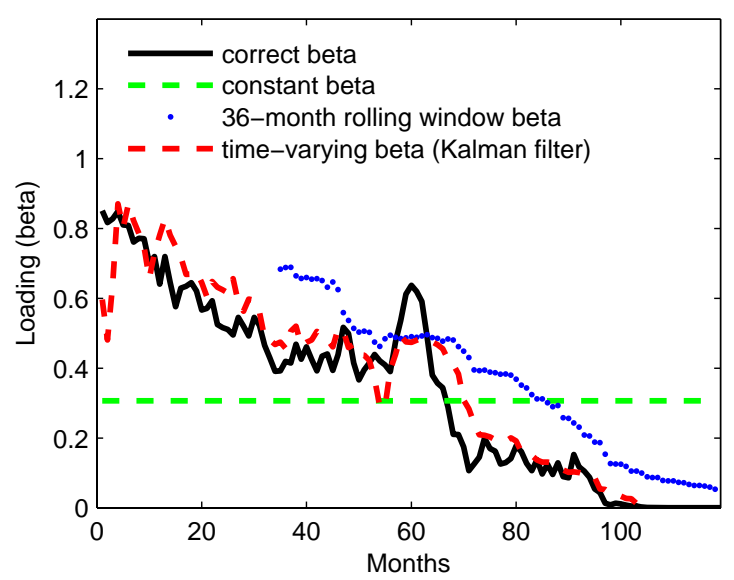

Panel B: Mixed Convertible-Bond Fund

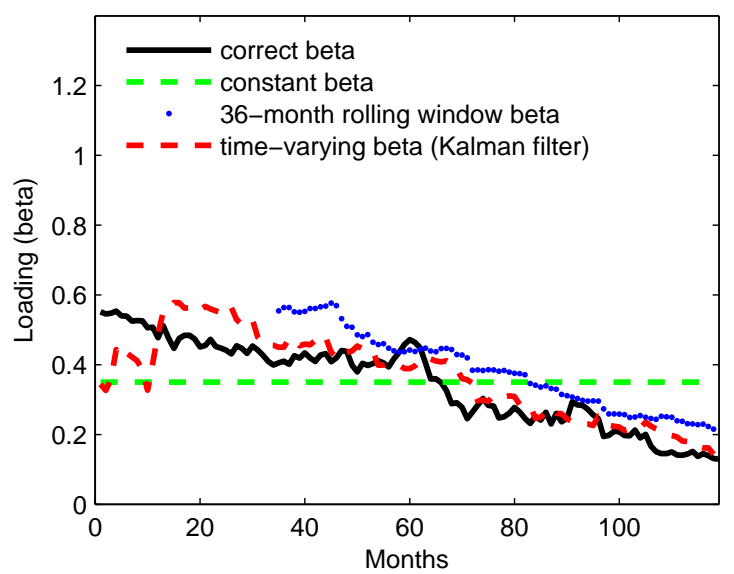




\section{Figure 2}

\section{Comparison of Alphas Obtained with Constant and Time-Varying Beta Models}

This figure compares alphas of CBFs obtained by two alternative models: (i) a Carhart (1997) model with constant loadings, as in Equation (1), and (ii) a Carhart (1997) model with a time-varying loading on the market factor, as formalized in Equation (3). 'Crosses' indicate funds with no significant alphas and 'circles' funds with statistically significant alphas under each of the two models. 'Triangles' indicate funds that display significant alphas only when using the constant-beta model as performance benchmark. The significance level is set at 5\%. Since the two models require the estimation of several parameters, only funds with more than 30 monthly observations are analyzed. Alphas refer to annualized values expressed in percentage points.

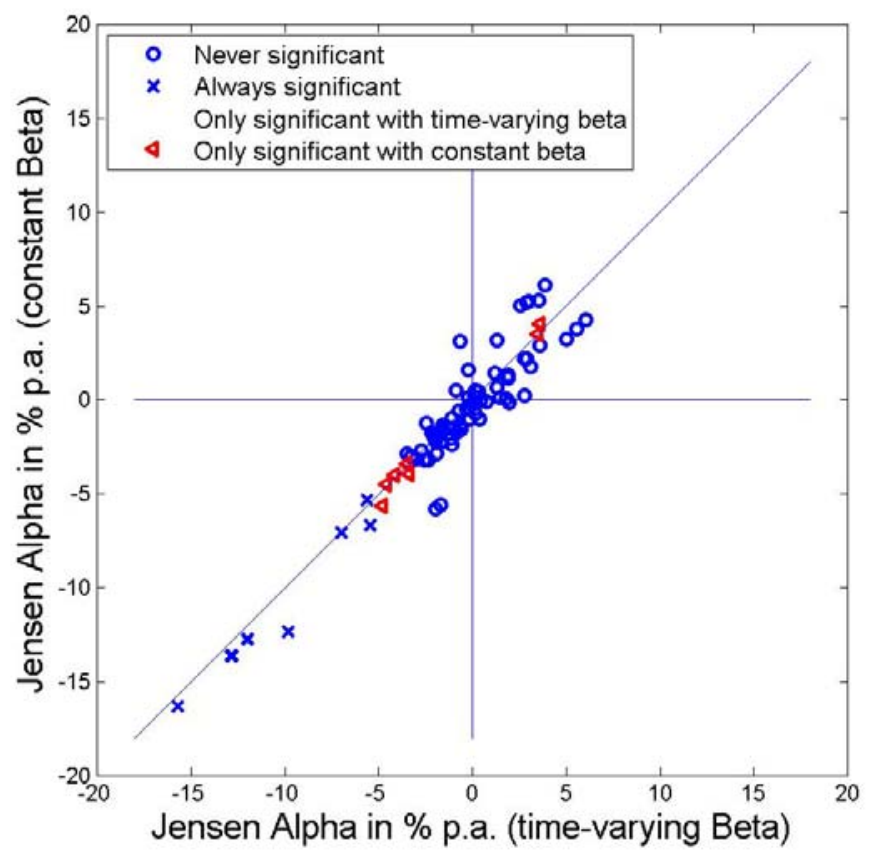


In spite of the arguments in favor of explicitly modeling time-varying betas, this issue might be of minor relevance for the purposes of this study. First, the example in Figure 1, Panel A, is rather extreme because the chosen stock beta of 1.5 is comparatively high and the maturity of the convertible bond reaches zero, favoring extreme values of delta. Second, CBFs typically hold several convertible securities in their portfolios, reducing variability in the overall funds' market beta through diversification. Third, CBFs are likely to adjust periodically their portfolios in order to substitute redeemed maturing issues and hold certain portfolio characteristics, such as duration and moneyness, constant over time. Finally, as documented in Section 2, CBFs also heavily invest in straight bonds and regular stocks, instruments that display a much less pronounced variation in market beta. To get a first insight about the effects of considering CBFs with more realistic portfolios, Figure 1, Panel B displays the evolution of beta for a CBF with an initial investment in two convertible bonds $(50 \%)$, the respective underlying stocks $(25 \%)$, and bonds with an assumed market beta of zero $(25 \%)$. Beta variability is substantially reduced, making the use of the latent variable model much less important. In fact, in this example, the RMSEs of the constant-beta, rolling-window, and latent-beta models amount to $0.12,0.10$, and 0.07 respectively.

Since the importance of capturing time-variability of betas when assessing the performance of CBFs is ultimately an empirical issue, in Figure 2 we compare two sets of alphas obtained by the constant-beta model of Equation (1) and the time-varying model of Equation (4), respectively. Funds tend to lie on the 45 degree line indicating no apparent systematic differences in alphas between the two models. In $83 \%$ of cases, both models indicate a non-significant alpha. For $10 \%$ of CBFs, both models detect a statistically 
significant alpha. Only in $7 \%$ of cases, the constant-beta model generates significant alphas, while the time-varying beta does not. On the contrary, it is never the case that alphas are significant in the time-varying beta model but not in the constant-beta model. Finally, there is no CBF for which the two models produce alphas with opposite signs, one of them being significant. Overall, accounting for time variation in betas does not seem to improve the results of a performance analysis. ${ }^{12}$ In view of these results and in order to work with parsimonious performance models, we refrain from adopting the Kalman filtering technique in the remainder of the paper. Instead, we follow the large bulk of the performance-measurement literature and use the conventional constant-beta performance model of Equation (1). ${ }^{13}$

We assess the factor-based performance models according to standard criteria. First, we provide for all examined factors an economic rationale (cf. Section 2). Second, to decide whether a new factor should be included in the factor model, we employ econometric tools that are generally accepted in the related literature: Fama and French (1993) analyze the significance of the factor loadings, the size of the factor loadings, the significances of the alphas, and the adjusted $\mathrm{R}^{2}$. Elton, Gruber, and Blake (1999) focus on the mean pairwise correlation of the residuals and the mean absolute value of the pairwise correlation of the residuals. If a model produces on average significantly lower absolute correlation values than a second model, this indicates the superiority of the former return generating process. Elton, Gruber, and Blake (1999) also perform a test to assess the significances of the

\footnotetext{
${ }^{12}$ It has to be noted that capturing time-variation in betas is likely to be of major importance when assessing the risk exposure of convertible-bond funds at a certain point in time.

${ }^{13}$ Conditional estimates of factor loadings and alphas can still be obtained by rolling regressions.
} 
coefficients in a time-series regression. They examine for each factor the number of times that the loading is significantly different from zero. In addition to the above-described methods, we will also make use of the Akaike and the Schwarz information criterion. We evaluate the models by using both time-series regressions and standard panel regressions and report panel corrected standard errors (PCSE).

\subsection{Analyzing Stock and Bond Factors}

As described in Section 3.1 and in Section 3.2, we use the following stock factors: MARKET, SMB, HML and UMD; and the following bond factors TERM, DEFT, HY and BOND. ${ }^{14}$

The Carhart (1997) four-factor model serves as a standard reference model for our further analysis:

$$
\text { FUND }_{i, t}=\alpha_{i}+\beta_{i, 1} \text { MARKET }_{t}+\beta_{i, 2} \operatorname{SMB}_{\mathrm{t}}+\beta_{\mathrm{i}, 3} \mathrm{HML}_{\mathrm{t}}+\beta_{\mathrm{i}, 4} \mathrm{UMD}_{\mathrm{t}}+\mathrm{e}_{\mathrm{i}, \mathrm{t}} \cdot
$$

The intercept of the model, $\alpha_{i}$, is the Carhart (1997) measure of abnormal performance. All further models are obtained by adding selected risk factors to the above equation. Table IV and Table V report panel and time-series results of the first-step analysis of stock- and bond models. In Table IV, all Carhart (1997) coefficients in the panel regressions are

\footnotetext{
${ }^{14}$ In order to cope with the problem of multicollinearity, we follow Blake, Elton, and Gruber (1999) and orthogonalize some variables before using them as regressors. In this study the following parameters are othogonalized: HY, BOND, VOLA, $\max (0, \text { MARKET-BOND), (MARKET) })^{2}$ CBI, CBAI and SD. All parameters are described in the text and in the Appendix.
} 
significantly different from zero for all tested models. Moreover, the slopes remain similar across regressions. The coefficients of the bond related factors TERM and DEFT demonstrate high significances if they are applied together. However, when tested separately, the coefficient of DEFT shows much higher values than TERM. Moreover, while DEFT is significantly different from zero, TERM is not. In terms of the values of the mean pairwise (absolute) residual correlations, the high yield index, HY, performs even better than DEFT. On the contrary, the bond index factor, BOND, does not generate a significant coefficient in the panel regression and shows a low percentage of significances in the time-series regression. The values for the adjusted $\mathrm{R}^{2}$, the Akaike criterion, and the Schwarz criterion indicate that the performance of the models can be improved by adding appropriate factors. Generally, the mean pairwise (absolute) residual correlations can be significantly reduced by adding appropriate factors to the Carhart (1997) model except for the DEFT factor. The relatively high percentage of significances in the time-series regressions of the high-yield factor $(\mathrm{HY})$ loadings confirms the importance of this default factor.

The results of the first-step analysis of stock- and bond models can be summarized as follows. First, the Carhart (1997) factors for stocks capture a large part of the variation in convertible bond fund returns. Second, the term-structure factor TERM appears to be an important explanatory factor, but only in combination with the default factor DEFT. Third, the high yield index, HY, captures more variation in returns than the common default factor DEFT. Fourth, a bond index factor, BOND, seems to capture only low variation in returns. Therefore, for our further analysis, we select models 1, 2 and, 7 tested in Table IV and Table V. 


\section{Comparison of Models with Panel Regressions}

This table reports the coefficients of the panel regression of the general form: $\mathrm{FUND}_{\mathrm{i}, \mathrm{t}}=\alpha_{\mathrm{i}}+\Sigma_{\mathrm{k}} \beta_{\mathrm{i}}^{\mathrm{k}} \cdot \mathrm{F}_{\mathrm{t}}^{\mathrm{k}}+\mathrm{e}_{\mathrm{i}, \mathrm{t}}$ and $\mathrm{F}_{\mathrm{t}}^{\mathrm{k}}$ are the factors in the performance model and $\mathrm{FUND}$ i,t are the monthly excess-returns of convertible bond fund i. The factors of the Carhart (1997) four-factor model are defined as follows: MARKET is the value-weight return on all NYSE, AMEX, and NASDAQ stocks (from CRSP) minus the one-month Treasury bill rate (from Ibbotson Associates), SMB (Small Minus Big) is the average return on three small portfolios minus the average return on three big portfolios, HML (High Minus Low) is the average return on two value portfolios minus the average return on two growth portfolios, UMD (Up Minus Down) is the average return on two high prior return portfolios minus the average return on two low prior return portfolios. The Carhart (1997) factors are from the Kenneth R. French data library on his webpage. Additional factors for generating return processes of stocks and bonds are: TERM is the caturn of the Lehm US Ge Co

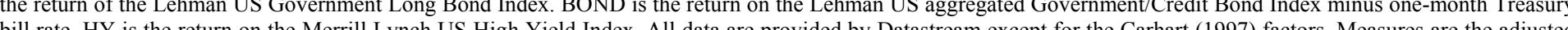
bill rate. HY is the return on the Merrill Lynch US High Yield Index. All data are provided by Datastream except for the Carhart (1997) factors. Measures are the adjusted

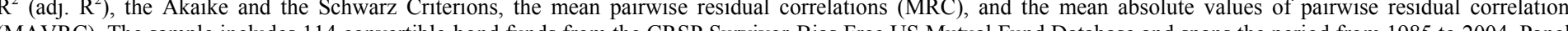
(MAVRC). The sample includes 14085 to 2004. Pane corrected standard errors (PCSE) are reported in parenthesis.

\begin{tabular}{|c|c|c|c|c|c|c|c|c|c|c|c|c|c|c|}
\hline \multirow[b]{3}{*}{$\begin{array}{l}\text { Model } \\
\text { No }\end{array}$} & \multirow[b]{3}{*}{ Alpha } & \multicolumn{8}{|c|}{ Factor Loadings } & \multirow{2}{*}{\multicolumn{5}{|c|}{ Measures }} \\
\hline & & \multicolumn{4}{|c|}{ Carhart (1997) four-factor model } & \multicolumn{4}{|c|}{$\begin{array}{l}\text { Additional factors: } \\
\text { return generating processes } \\
\text { of stocks and bonds }\end{array}$} & & & & & \\
\hline & & MARKET & SMB & HML & UMD & TERM & DEFT & BOND & HY & Adj $R^{2}$ & $\begin{array}{l}\text { Akaike } \\
\text { Criterion }\end{array}$ & $\begin{array}{l}\text { Schwarz } \\
\text { Criterion }\end{array}$ & MRC & MAVRC \\
\hline 1 & $\begin{array}{r}-0.001 \\
(0.001)\end{array}$ & $\begin{array}{l}0.680 * \star * \\
(0.019)\end{array}$ & $\begin{array}{l}0.139 * * * \\
(0.023)\end{array}$ & $\begin{array}{l}0.072 \text { *** } \\
(0.028)\end{array}$ & $\begin{array}{l}0.093 \text { *** } \\
(0.016)\end{array}$ & & & & & 0.69 & -4.99 & -4.98 & 0.37 & 0.41 \\
\hline 2 & $\begin{array}{r}-0.001 \\
(0.001)\end{array}$ & $\begin{array}{l}0.648 \text { *** } \\
(0.019)\end{array}$ & $\begin{array}{l}0.123 \text { *** } \\
(0.023)\end{array}$ & $\begin{array}{l}0.050 \text { * } \\
(0.027)\end{array}$ & $\begin{array}{l}0.106 \text { *** } \\
(0.016)\end{array}$ & $\begin{array}{l}0.091 * \star \star \\
(0.034)\end{array}$ & $\begin{array}{l}0.282 * * * \\
(0.079)\end{array}$ & & & 0.70 & -5.01 & -5.00 & 0.35 & 0.39 \\
\hline 3 & $\begin{array}{r}-0.001 \\
(0.001)\end{array}$ & $\begin{array}{l}0.680 \text { *** } \\
(0.019)\end{array}$ & $\begin{array}{l}0.141 \text { *** } \\
(0.023)\end{array}$ & $\begin{array}{l}0.071 \text { ** } \\
(0.028)\end{array}$ & $\begin{array}{l}0.092 \text { *** } \\
(0.016)\end{array}$ & $\begin{array}{l}0.017 \\
(0.028)\end{array}$ & & & & 0.69 & -4.99 & -4.98 & 0.36 & 0.40 \\
\hline 4 & $\begin{array}{r}-0.001 \\
(0.001)\end{array}$ & $\begin{array}{l}0.662 * \star \\
(0.019)\end{array}$ & $\begin{array}{l}0.124 \text { *** } \\
(0.023)\end{array}$ & $\begin{array}{l}0.061 \text { ** } \\
(0.028)\end{array}$ & $\begin{array}{l}0.103 * \star * \\
(0.016)\end{array}$ & & $\begin{array}{l}0.171 \text { *** } \\
(0.063)\end{array}$ & & & 0.70 & -5.00 & -4.99 & 0.38 & 0.41 \\
\hline 5 & $\begin{array}{r}-0.001 \\
(0.001)\end{array}$ & $\begin{array}{l}0.682 \text { *** } \\
(0.018)\end{array}$ & $\begin{array}{l}0.138 \text { *** } \\
(0.023)\end{array}$ & $\begin{array}{l}0.072 \text { *** } \\
(0.028)\end{array}$ & $\begin{array}{l}0.093 \text { *** } \\
(0.016)\end{array}$ & & & $\begin{array}{l}0.053 \\
(0.052)\end{array}$ & & 0.69 & -4.99 & -4.98 & 0.36 & 0.40 \\
\hline 6 & $\begin{array}{r}-0.001 \\
(0.001)\end{array}$ & $\begin{array}{l}0.673 * \star * \\
(0.017)\end{array}$ & $\begin{array}{l}0.148 \text { *** } \\
(0.021)\end{array}$ & $\begin{array}{l}0.072 * * * \\
(0.026)\end{array}$ & $\begin{array}{l}0.092 * \star * \\
(0.015)\end{array}$ & $\begin{array}{l}0.011 \\
(0.025)\end{array}$ & & & $\begin{array}{l}0.269 * * \star \\
(0.043)\end{array}$ & 0.71 & -5.04 & -5.03 & 0.33 & 0.37 \\
\hline 7 & $\begin{array}{r}-0.001 \\
(0.001)\end{array}$ & $\begin{array}{l}0.677 \text { *** } \\
(0.017)\end{array}$ & $\begin{array}{l}0.144 \text { *** } \\
(0.021)\end{array}$ & $\begin{array}{l}0.073 \text { *** } \\
(0.026)\end{array}$ & $\begin{array}{l}0.093 \text { *** } \\
(0.015)\end{array}$ & & & & $\begin{array}{l}0.257 \text { *** } \\
(0.041)\end{array}$ & 0.71 & -5.04 & -5.03 & 0.35 & 0.39 \\
\hline
\end{tabular}




\section{Table V \\ Percentage of Significant Time-Series Regression Coefficients}

This table reports the percentage of time-series regression coefficients that are different from zero at the $10 \%$ level for convertible-bond funds when a time-series regression is run on the excess-returns for each fund against the factors of the selected model (estimated standard errors are adjusted for autocorrelation and heteroskedasticity according to Newey and West, 1987). The time-series regression are of the general form: $F_{U N D} D_{i, t}=\alpha_{i}+\Sigma_{k} \beta_{i}^{k} \cdot F^{k}{ }_{t}+e_{i, t}$ and $F^{k}{ }_{t}$ are the factors in the performance model and $\mathrm{FUND}_{\mathrm{i}, \mathrm{t}}$ are the monthly excess-returns of convertible bond fund $\mathrm{i}$. The factors of the Carhart (1997) four-factor model are as follows: MARKET is the value-weight return on all NYSE, AMEX, and NASDAQ stocks (from CRSP) minus the one-month Treasury bill rate (from Ibbotson Associates), SMB (Small Minus Big) is the average return on three small portfolios minus the average return on three big portfolios, HML (High Minus Low) is the average return on two value portfolios minus the average return on two growth portfolios, UMD (Up Minus Down) is the average return on two high prior return portfolios minus the average return on two low prior return portfolios. The Carhart (1997) factors are from the Kenneth R. French data library on his webpage. Additional factors for generating return processes of stocks and bonds are: TERM is the return of the Lehman US Government Long Bond Index minus the one-month Treasury bill rate. DEFT is the return on the Lehman US Corporate Long Bond Index minus the return of the Lehman US Government Long Bond Index. BOND is the return on the Lehman US aggregated Government/Credit Bond Index minus one-month Treasury bill rate. HY is the return on the Merrill Lynch US High Yield Index. All data are provided by Datastream except for the Carhart (1997) factors. The sample includes 114 convertible-bond funds from the CRSP Survivor-Bias Free US Mutual Fund Database and spans the period from 1985 to 2004 .

\begin{tabular}{|c|c|c|c|c|c|c|c|c|c|}
\hline \multirow[b]{3}{*}{$\begin{array}{c}\text { Model } \\
\mathrm{Nr} .\end{array}$} & \multirow[b]{3}{*}{ Alpha } & \multicolumn{8}{|c|}{ Model Factors } \\
\hline & & \multicolumn{4}{|c|}{ Carhart (1997) four-factor model } & \multicolumn{4}{|c|}{$\begin{array}{l}\text { Additional factors: } \\
\text { return generating processes } \\
\text { of stocks and bonds }\end{array}$} \\
\hline & & MARKET & SMB & HML & UMD & TERM & DEFT & BOND & $\mathrm{HY}$ \\
\hline 1 & $28 \%$ & $96 \%$ & $63 \%$ & $50 \%$ & $43 \%$ & & & & \\
\hline 2 & $24 \%$ & $96 \%$ & $61 \%$ & $41 \%$ & $50 \%$ & $41 \%$ & $25 \%$ & & \\
\hline 3 & $28 \%$ & $96 \%$ & $68 \%$ & $50 \%$ & $46 \%$ & $31 \%$ & & & \\
\hline 4 & $27 \%$ & $96 \%$ & $59 \%$ & $52 \%$ & $54 \%$ & & $15 \%$ & & \\
\hline 5 & $29 \%$ & $97 \%$ & $69 \%$ & $51 \%$ & $45 \%$ & & & $34 \%$ & \\
\hline 6 & $29 \%$ & $97 \%$ & $67 \%$ & $44 \%$ & $44 \%$ & $35 \%$ & & & $61 \%$ \\
\hline 7 & $32 \%$ & $98 \%$ & $64 \%$ & $48 \%$ & $42 \%$ & & & & $67 \%$ \\
\hline
\end{tabular}




\subsection{Analyzing Option Factors}

In this subsection, we extend the models presented so far by factors addressing the optionlike character of convertible bonds. As described in Section 3.3, we analyze six possible factors that may prove useful for extending the current models.

The results of the second-step analysis of stock-, bond- and convertible-bond models are presented in Table VI and Table VII. In Table VI, the Carhart (1997) coefficients of the panel regressions are still significantly different from zero for all models tested. The results are similar to the models of stocks and bonds. In addition, the slopes remain comparable across the different regressions. The three examined additional convertible bond factors VOLA, $\max (0, M A R K E T-B O N D)$ and (MARKET $)^{2}$ show no significant factor-loadings in the panel-regressions. The time-series regressions in Table VII confirm that result: the coefficients are not significant at the $10 \%$ level for more than $82 \%$ of the funds. The measures in Table VI demonstrate that the adjusted $\mathrm{R}^{2}$, the Akaike and Schwarz Criteria, and the mean pairwise (absolute) residual correlations remain almost unchanged (statistically) compared to the standard Carhart (1997) model if one of these three factors is added. However, the fourth examined factor, the convertible bond index, CBI, shows high and significant loadings. Moreover, the adjusted $\mathrm{R}^{2}$, the Akaike and Schwarz criterion, and the mean pairwise (absolute) residual correlations are further improved (especially the residual correlation is significantly lower). Similar results are obtained in the time-series regressions of each fund in Table VII. In regressions 11, 12, and 13, the sensitivities on the convertible bond index are significant for a quite large percentage of funds, whereas the significances of the stock and bond related factors remain almost unchanged. 
Additionally (not reported in Table VI), similar to Agarwal and Naik (2004), we extend the analysis of non-linear factors for convertible bond fund returns with option-based factors consisting of liquid at-the-money (ATM) and out-of-the-money (OTM) European call and put options on the S\&P 500 index. However, similar to the non-linear factors $\max (0, \text { MARKET-BOND) and (MARKET })^{2}$, the examined additional option-based factors based on S\&P 500 call and put option time series show no significant factor-loadings in the panel-regressions in the sub-period between January 1996 and December 2004.

The results of the second-step analysis of stock, bond, and convertible bond models can be summarized as follows. First, volatility does not seem to be an important factor as implied volatility fails to capture important variation of convertible bond fund returns. Second, neither the non-linear factors nor the option-based factors capture variations in CBF returns. As we have seen above, $59 \%$ of the convertible bond fund in our sample show normally distributed returns. Therefore, non-linear factors are assumed not to be significant. Third, among the four convertible-bond-specific factors, the convertible bond index is the most successful in capturing the residual variation in convertible bond fund returns. We know that convertible-bond funds mainly consist of stocks, bonds, and convertible bonds. Therefore, we expect stock returns (and the returns of the pure equitylike convertible bonds) to be explained by the stock related factors and bond returns (and the returns of the pure debt-like convertible bonds) by the bond related factors (or by the stock and bond factors). The residual unexplained variation in returns, which is attributable to convertible bond specific factors, is at least partially captured by the convertible bond index. Therefore, the models of regressions 11, 12, and 13 are selected as models for the 
return processes of stocks, bonds, and convertible bonds, in which convertible-bond funds invest primarily.

So far in this section, we have developed a set of factor-based performance models. The proposed models are likely to capture the variation of CBF returns and will thus serve as the basis of the cross-sectional analysis in the next subsection. More precisely, we apply three models using stock and bond related factors, (i)-(iii), and three models using factors related to stocks, bonds, and convertible bonds, (iv)-(vi):

(i) CARHART (MARKET, SMB HML, and UMD),

(ii) CARHART + TERM + DEFT,

(iii) CARHART + HY,

(iv) CARHART + CBI,

(v) CARHART + TERM + DEFT + CBI, and

(vi) CARHART $+\mathrm{HY}+\mathrm{CBI}$. 


\section{Comparison of Models Including a Convertible Bond Factor}

This table reports the coefficients of the panel regression of the general form: $\mathrm{FUND}_{\mathrm{i}, \mathrm{t}}=\alpha_{\mathrm{i}}+\Sigma_{\mathrm{k}} \beta_{\mathrm{i}}^{\mathrm{k}} \cdot \mathrm{F}_{\mathrm{t}}^{\mathrm{k}}+\mathrm{e}_{\mathrm{i}, \mathrm{t}}$ and $\mathrm{F}_{\mathrm{t}}^{\mathrm{k}}$ are the factors in the performance model and FUND ${ }_{\mathrm{i}, \mathrm{t}}$ are the monthly excessreturns of convertible bond fund $i$. The factors of the Carhart (1997) four-factor model are defined as follows: MARKET is the value-weight return on all NYSE, AMEX, and NASDAQ stocks (from CRSP) minus the one-month Treasury bill rate (from Ibbotson Associates), SMB (Small Minus Big) is the average return on three small portfolios minus the average return on three big portfolios, HML (High Minus Low) is the average return on two value portfolios minus the average return on two growth portfolios, UMD (Up Minus Down) is the average return on two high portfolios, HML (High Minus Low) is the average return on two value portfolios minus the average return on two growth portfolios, UMD (Up Minus Down) is the average return on two high
prior return portfolios minus the average return on two low prior return portfolios. The Carhart (1997) factors are from the Kenneth R. French data library on his webpage. Additional factors for prior return portfolios minus the average return on two low prior return portfolios. The Carhart (1997) factors are from the Kenneth R. French data library on his webpage. Additional factors for
generating return processes of stocks and bonds are: TERM is the return of the Lehman US Government Long Bond Index minus the one-month Treasury bill rate. DEFT is the return on the generating return processes of stocks and bonds are: TERM is the return of the Lehman US Government Long Bond Index minus the one-month Treasury bill rate. DEFT is the return on the Lehman US Corporate Long Bond Index minus the return of the Lehman US Government Long Bond Index. HY is the return on the Merrill Lynch US High Yield Index. VOLA is the return on the
CBOE Volatility VXO Index. max(0,MARKET-BOND) is the maximum of zero and the value-weight return on all NYSE, AMEX, and NASDAQ stocks (from CRSP) minus the return on the Lehman US aggregated Government/Credit Bond Index. (MARKET) ${ }^{2}$ is the value-weight return on all NYSE, AMEX, and NASDAQ stocks (from CRSP) minus the one-month Treasury bill rate (from Ibbotson Associates) squared. CBI is the return on the Merrill Lynch All US Convertible Bond Index. All data are provided by Datastream except for the Carhart (1997) factors. Measures are the adjusted $\mathrm{R}^{2}$ (adj. $\mathrm{R}^{2}$ ), the Akaike and the Schwarz Criterions, the mean pairwise residual correlations (MRC), and the mean absolute values of pairwise residual correlations (MAVRC). The sample includes 114 convertible-bond funds from the CRSP Survivor-Bias Free US Mutual Fund Database and spans the period from 1985 to 2004. Panel-corrected standard errors (PCSE) are reported in parenthesis.

\section{Factor Loadings}

\begin{tabular}{|c|c|c|c|c|c|c|c|c|c|c|}
\hline \multicolumn{4}{|c|}{ Carhart (1997) four-factor model } & \multicolumn{3}{|c|}{$\begin{array}{l}\text { Additional factors for } \\
\text { return generating processes } \\
\text { of stocks and bonds }\end{array}$} & \multicolumn{4}{|c|}{$\begin{array}{l}\text { Additional factors for } \\
\text { convertible bonds }\end{array}$} \\
\hline MARKET & SMB & HML & UMD & TERM & DEFT & HY & VOLA & $\underset{\text { (O,MAREXT-BOND) }}{\max }$ & (MARKET) $^{2}$ & CBI \\
\hline
\end{tabular}

Panel A: Taking into account the convertible bond factor

\begin{tabular}{|c|c|c|c|c|c|c|c|c|c|c|c|c|c|c|c|c|}
\hline \multicolumn{12}{|c|}{ Panel A: Taking into account the convertible bond factor } & \multirow{2}{*}{0.69} & \multirow[b]{2}{*}{-4.98} & \multirow[b]{2}{*}{-4.98} & \multirow[b]{2}{*}{0.37} & \multirow[b]{2}{*}{0.40} \\
\hline 8 & $\begin{array}{r}-0.001 \\
(0.001)\end{array}$ & $\begin{array}{l}0.680 * * * \\
(0.019)\end{array}$ & $\begin{array}{l}0.138 * \star \star \\
(0.023)\end{array}$ & $\begin{array}{l}0.071 \text { ** } \\
(0.028)\end{array}$ & $\begin{array}{l}0.092 \text { *** } \\
(0.016)\end{array}$ & & & $\begin{array}{l}0.004 \\
(0.005)\end{array}$ & & & & & & & & \\
\hline 9 & $\begin{array}{r}-0.001 \\
(0.001)\end{array}$ & $\begin{array}{l}0.682 \text { *** } \\
(0.019)\end{array}$ & $\begin{array}{l}0.141 \text { *** } \\
(0.023)\end{array}$ & $\begin{array}{l}0.075 \text { *** } \\
(0.028)\end{array}$ & $\begin{array}{l}0.094 \text { ** } \\
(0.016)\end{array}$ & & & & $\begin{array}{r}-0.070 \\
(0.045)\end{array}$ & & & 0.69 & -4.99 & -4.98 & 0.37 & 0.40 \\
\hline 10 & $\begin{array}{r}-0.001 \\
(0.001)\end{array}$ & $\begin{array}{l}0.683 \text { *** } \\
(0.020)\end{array}$ & $\begin{array}{l}0.143 \text { *** } \\
(0.023)\end{array}$ & $\begin{array}{l}0.076 \text { *** } \\
(0.028)\end{array}$ & $\begin{array}{l}0.094 \text { *** } \\
(0.016)\end{array}$ & & & & & $\begin{array}{r}-0.264 \\
(0.187)\end{array}$ & & 0.69 & -4.99 & -4.98 & 0.38 & 0.41 \\
\hline 11 & $\begin{array}{r}-0.001 \\
(0.001)\end{array}$ & $\begin{array}{l}0.693 \text { *** } \\
(0.019)\end{array}$ & $\begin{array}{l}0.149 * * * \\
(0.021)\end{array}$ & $\begin{array}{l}0.085 \text { *** } \\
(0.026)\end{array}$ & $\begin{array}{l}0.093 \text { *** } \\
(0.015)\end{array}$ & & & & & & $\begin{array}{l}0.250 \text { *** } \\
(0.038)\end{array}$ & 0.71 & -5.06 & -5.06 & 0.29 & 0.34 \\
\hline \multicolumn{12}{|c|}{ Panel B: Models for Convertible Bond Funds } & & & & & \\
\hline 12 & $\begin{array}{r}-0.001 \\
(0.001)\end{array}$ & $\begin{array}{l}0.661 \text { *** } \\
(0.020)\end{array}$ & $\begin{array}{l}0.132 \text { *** } \\
(0.022)\end{array}$ & $\begin{array}{l}0.064 \text { ** } \\
(0.026)\end{array}$ & $\begin{array}{l}0.106 \\
(0.016)\end{array}$ & $\begin{array}{l}0.085 \text { ** } \\
(0.033)\end{array}$ & $\begin{array}{l}0.273 \text { *** } \\
(0.078)\end{array}$ & & & & $\begin{array}{l}0.234 \text { *** } \\
(0.038)\end{array}$ & 0.71 & -5.07 & -5.06 & 0.28 & 0.33 \\
\hline 13 & $\begin{array}{r}-0.001 \\
(0.001)\end{array}$ & $\begin{array}{l}0.687 \text { *** } \\
(0.018)\end{array}$ & $\begin{array}{l}0.152 \text { *** } \\
(0.020)\end{array}$ & $\begin{array}{l}0.084 \text { *** } \\
(0.024)\end{array}$ & $\begin{array}{l}0.093 \text { *** } \\
(0.014)\end{array}$ & & & $\begin{array}{l}0.213 \text { *** } \\
(0.040)\end{array}$ & & & $\begin{array}{l}0.221 \text { *** } \\
(0.036)\end{array}$ & 0.72 & -5.10 & -5.09 & 0.28 & 0.32 \\
\hline
\end{tabular}




\section{Table VII \\ Percentage of Significant Time-Series Regression Coefficients for Models including a Convertible-Bond Factor}

This table reports the percentage of time-series regression coefficients that are different from zero at the $10 \%$ level for convertible-bond funds when a time-series regression is run on the excess-returns for each fund against the factors of the selected model (estimated standard errors are adjusted for autocorrelation and heteroskedasticity according to Newey and West, 1987). The time-series regression are of the general form: $F U N D_{i, t}=\alpha_{i}+\Sigma_{k} \beta_{i}^{k} \cdot F_{t}^{k}+e_{i, t}$ and $F_{t}^{k}$ are the factors in the performance model and $\mathrm{FUND}_{\mathrm{i}, \mathrm{t}}$ are the monthly excess-returns of convertible bond fund $\mathrm{i}$. The factors of the Carhart (1997) four-factor model are as follows: MARKET is the value-weighted return on all NYSE, AMEX, and NASDAQ stocks (from CRSP) minus the one-month Treasury bill rate (from Ibbotson Associates), SMB (Small Minus Big) is the average return on three small portfolios minus the average return on three big portfolios, HML (High Minus Low) is the average return on two value portfolios minus the average return on two growth portfolios, UMD (Up Minus Down) is the average return on two high prior return portfolios minus the average return on two low prior return portfolios. The Carhart (1997) factors are from the Kenneth R. French data library on his webpage. Additional factors for generating return processes of stocks and bonds are: TERM is the return of the Lehman US Government Long Bond Index minus the one-month Treasury bill rate. DEFT is the return on the Lehman US Corporate Long Bond Index minus the return of the Lehman US Government Long Bond Index. HY is the return on the Merrill Lynch US High Yield Index. VOLA is the return on the CBOE Volatility VXO Index. max(0,MARKET-BOND) is the maximum of zero and the value-weight return on all NYSE, AMEX, and NASDAQ stocks (from CRSP) minus the return on the Lehman US aggregated Government/Credit Bond Index. (MARKET) ${ }^{2}$ is the value-weight return on all NYSE, AMEX, and NASDAQ stocks (from CRSP) minus the one-month Treasury bill rate (from Ibbotson Associates) squared. CBI is the return on the Merrill Lynch All US Convertible Bond Index. All data are provided by Datastream except for the Carhart (1997) factors. The sample includes 114 convertible-bond funds from the CRSP Survivor-Bias Free US Mutual Fund Database and spans the period from 1985 to 2004.

\begin{tabular}{|c|c|c|c|c|c|c|c|c|c|c|c|}
\hline \multirow[b]{3}{*}{$\begin{array}{l}\text { Model } \\
\text { No }\end{array}$} & \multicolumn{11}{|c|}{ Model Factors } \\
\hline & \multicolumn{5}{|c|}{ Carhart (1997) four-factor model } & \multicolumn{2}{|c|}{$\begin{array}{l}\text { Additional factors: } \\
\text { return generating } \\
\text { processes of } \\
\text { stocks and bonds }\end{array}$} & \multicolumn{4}{|c|}{$\begin{array}{c}\text { Additional factors for } \\
\text { convertible bonds }\end{array}$} \\
\hline & Alpha & MARKET & $\mathrm{SMB}$ & HML & UMD & TERM DEFT & $\mathrm{HY}$ & VOLA & $\begin{array}{c}\max \\
(0, \text { MARKET- } \\
\text { BOND) }\end{array}$ & $(\text { MARKET) })^{2}$ & $\mathrm{CBI}$ \\
\hline
\end{tabular}

Panel A: Taking into account a convertible bond factor

\begin{tabular}{cccccccc}
\hline 8 & $23 \%$ & $96 \%$ & $63 \%$ & $49 \%$ & $39 \%$ & $12 \%$ & \\
9 & $32 \%$ & $96 \%$ & $68 \%$ & $57 \%$ & $46 \%$ & $18 \%$ & $13 \%$ \\
10 & $28 \%$ & $94 \%$ & $58 \%$ & $44 \%$ & $43 \%$ & $42 \%$ \\
11 & $24 \%$ & $97 \%$ & $66 \%$ & $50 \%$ & $46 \%$ & & 40 \\
\hline
\end{tabular}

Panel B: Models for Convertible Bond Funds

\begin{tabular}{|c|c|c|c|c|c|c|c|c|}
\hline 12 & $19 \%$ & $93 \%$ & $59 \%$ & $41 \%$ & $50 \%$ & $39 \%$ & $36 \%$ & $33 \%$ \\
\hline 13 & $30 \%$ & $99 \%$ & $67 \%$ & $52 \%$ & $49 \%$ & & $51 \%$ & $45 \%$ \\
\hline
\end{tabular}




\subsection{Cross-Sectional Evidence}

In this subsection, we investigate whether the performance of convertible-bond funds as determined by the six selected models is related to fund-specific characteristics. Similar to the study of Kacperczyk, Sialm, and Zheng (2005), we perform a multivariate crosssectional panel regression. The dependent variable, PERF, measures the monthly performance (abnormal return) as obtained by the six selected performance models (Panel A to Panel F in Table VIII). First, we estimate factor loadings by using three years of lagged data. Subsequently, we subtract expected returns (calculated in accordance with the models) from realized returns to determine the abnormal return in each month. We take into account possible time variations in the factor loadings of individual funds by using past data to estimate the factor sensitivities and determine the abnormal returns during a subsequent periods. The abnormal returns of fund $\mathrm{i}$ at time $\mathrm{t}\left(\mathrm{PERF}_{\mathrm{i}, \mathrm{t}}\right)$ are calculated as follows:

$$
\operatorname{PERF}_{\mathrm{i}, \mathrm{t}}=\mathrm{FUND}_{\mathrm{i}, \mathrm{t}}-\sum_{\mathrm{k}} \beta_{\mathrm{i}, \mathrm{t}-1}^{\mathrm{k}} \mathrm{F}_{\mathrm{t}}^{\mathrm{k}} \text {. }
$$

$\mathrm{F}_{\mathrm{t}}^{\mathrm{k}}$ are the factors in the performance model, $\beta_{\mathrm{i}, \mathrm{t}-1}^{\mathrm{k}}$ are the estimated betas, and $\mathrm{R}_{\mathrm{i}, \mathrm{t}}-\mathrm{R}_{\mathrm{F}, \mathrm{t}}$ are the monthly excess-returns of convertible bond fund $i$.

Next, we regress the abnormal returns of each convertible-bond fund in each month on the holding-based explanatory variables and other fund characteristics. Mitigating potential endogeneity problems, we lag all explanatory variables by one month. Table VIII reports coefficients of the monthly panel and multivariate cross-sectional regression of the general form: 


$$
\mathrm{PERF}_{\mathrm{i}, \mathrm{t}}=\mathrm{c}+\chi_{1} \mathrm{HV}_{\mathrm{i}, \mathrm{t}-1}+\chi_{2} \mathrm{LNTNA}_{\mathrm{i}, \mathrm{t}-1}+\chi_{3} \mathrm{ACTIVE}_{\mathrm{i}, \mathrm{t}-1}+\chi_{4} \mathrm{NMG}_{\mathrm{i}, \mathrm{t}-1}+\chi_{5} \mathrm{EXP}_{\mathrm{i}, \mathrm{t}-1}+\varepsilon_{\mathrm{i}, \mathrm{t}}
$$

HV represents the holding-based variables defined as percentages invested in convertible bonds (CB), stocks (S), bonds including convertibles ${ }^{15}(\mathrm{~B})$, convertible bonds minus stocks (CB-S), and bonds including convertibles minus stocks (B-S), respectively. We denote the natural logarithm of total net assets by LNTNA, the new-money growth per month by NMG, and the expense ratio by EXP. The variable ACTIVE is a dummy variable assuming a value of one if the convertible bond fund is active and zero otherwise. We estimate the regressions with panel-corrected standard errors (PCSE). The PCSE specification adjusts for the contemporaneous correlation and heteroskedasticity among returns as well as for autocorrelation within each fund's returns (Beck and Katz, 1995). The sample includes convertible-bond funds from the CRSP Survivor-Bias Free US Mutual Fund Database and spans the period from 1995 to 2004 (including the data used for calculating the abnormal returns).

Table VIII shows the results of the multivariate cross-sectional analysis. Interestingly, for all six models, there is a strongly significant positive relationship between the performance of convertible-bond funds and the difference between the percentage invested in convertible bonds and the percentage invested in stocks (CB-S). Further, for all models tested, we find a significant positive link between fund performance and the percentage invested in convertible bonds (CB), and, for five out of the six models, a significant

\footnotetext{
${ }^{15}$ The definition of the data item "percentage invested in bonds" in the CRSP database includes convertible bonds. However, the database allows to clearly identify the "percentage invested in convertible bonds" only.
} 
negative relation between the fund performance and the percentage invested in stocks (S). Overall, the results in Table VIII indicate that convertible-bond funds with large convertible-bond holdings and low (or even negative) stock holdings generate, on average, higher abnormal returns. This relation is positive and significant if we determine the performance of convertible-bond funds by using the standard Carhart (1997) four-factor model, even when adding factors such as TERM, DEFT, HY, and CBI, or a combination of thereof. The results in Table VIII do not show a relation between the fund performance and the two other holding-based variables (B and B-S). The total net assets (LNTNA) tend to be negatively related to the fund performance. Not surprisingly, the active funds (ACTIVE) as well as the funds with a high new-money growth (NMG) tend to outperform dead funds and funds with low new-money growth, respectively. The coefficients related to expenses (EXP) are all highly negative, but are not statistically significant due to the large standard deviations. Finally, the presented results are fairly robust with respect to the model choice.

Possible explanations for the strong relation between fund performance and CB-S, CB, and S are: (1) CBF managers have excellent convertible-bond but poor stock selection skills; (2) Conversion does occur in many cases and shares of companies that issue convertibles and tend to underperform (see Arshanapalli, Fabozzi, Switzer and Gosselin 2005) are kept in the portfolios; (3) The variable CB-S (long convertible bonds and short stocks) can be interpreted as a proxy for convertible-bond arbitrage activity. Funds might be tempted to 
exploit misvaluations in the convertible-bond market ${ }^{16}$ by buying underpriced convertible bonds and shorting, when possible, the corresponding stock, a strategy typically employed by hedge funds; (4) The performance of CBFs is supposed to be influenced by the activities of convertible arbitrageurs. For instance, Evans (2002) reports that in 2001, 70\% of all new convertible-bond issues were bought by hedge funds. Therefore, he claims that convertible-arbitrage hedge funds dominate the convertible-bond market and influence both convertible-bond prices and stock prices via short selling. Since no factor in the models presented so far is specifically designed to explain returns driven by convertible arbitrage, it is possible that the above holding-based cross-sectional findings result from incorrectly specified data-generating processes. To test this hypothesis, we extend the models by adding convertible arbitrage related factors (an arbitrage index, CBAI, and an opportunity set factor, SD) in the next section.

\footnotetext{
${ }^{16}$ Several studies, such as King (1986), Carayannopoulos and Kalimipalli (2003), Ammann, Kind, and Wilde (2003), Ammann, Kind, and Wilde (2007) and others, document that market prices for convertible bonds substantially deviate from "fair" values as determined by conventional no-arbitrage models.
} 
Table VIII

Multivariate Panel Regression Evidence

This table reports the coefficients of the monthly panel and multivariate cross-sectional regression of the general form: $\operatorname{PERF}_{\mathrm{i}, t}=\mathbf{c}+\chi_{1} \mathrm{HV}_{\mathrm{i}, \mathrm{t}}$ ${ }_{1}+\chi_{2} \mathrm{LNTNA}_{\mathrm{i}, \mathrm{t}-1}+\chi_{3} \mathrm{ACTIVE}_{\mathrm{i}, \mathrm{t}-1}+\chi_{4} \mathrm{NMG}_{\mathrm{i}, \mathrm{t}-1}+\chi_{5} \mathrm{EXP}_{\mathrm{i}, \mathrm{t}-1}+\varepsilon_{\mathrm{i}, \mathrm{t}}$ where HV stands for the holding-based variables: CB-S, S, B, CB and B-S. The dependent variable, PERF, measures the monthly performance (abnormal return) using different performance models (Panel A to Panel F) based on 36 months of lagged data to determine the betas in the performance models. The abnormal returns are calculated as follows: $\mathrm{PERF}_{\mathrm{i}, \mathrm{t}}=\mathrm{FUND}_{\mathrm{i}, \mathrm{t}} \Sigma_{\mathrm{k}} \beta_{\mathrm{i}, \mathrm{t}-\mathrm{l}}^{\mathrm{k}} \mathrm{F}_{\mathrm{t}}^{\mathrm{k}}$ and $\mathrm{F}_{\mathrm{t}}^{\mathrm{k}}$ are the factors in the performance model. The holding-based variables are the asset compositions in percentages invested in convertible bonds (CB), stocks (S), bonds inclusive convertible bonds (B), convertible bonds minus stocks (CB-S) and bonds inclusive convertible bonds minus stocks (B-S), respectively. We denote the natural logarithm of total net assets by LNTNA, the new money growth per month by NMG and the expense ration by EXP. The variable ACTIVE is a dummy variable that is one if the convertible bond fund is active and zero otherwise. Mitigating potential endogeneity problems, we lag all explanatory variables by one month. The sample includes convertible-bond funds from the CRSP Survivor-Bias Free US Mutual Fund Database and spans the period from 1995 to 2004 (including the data used for calculating the abnormal returns). Panel-corrected standard errors (PCSE) are reported in parenthesis.

Dependent Variable: Monthly Performance (\%)

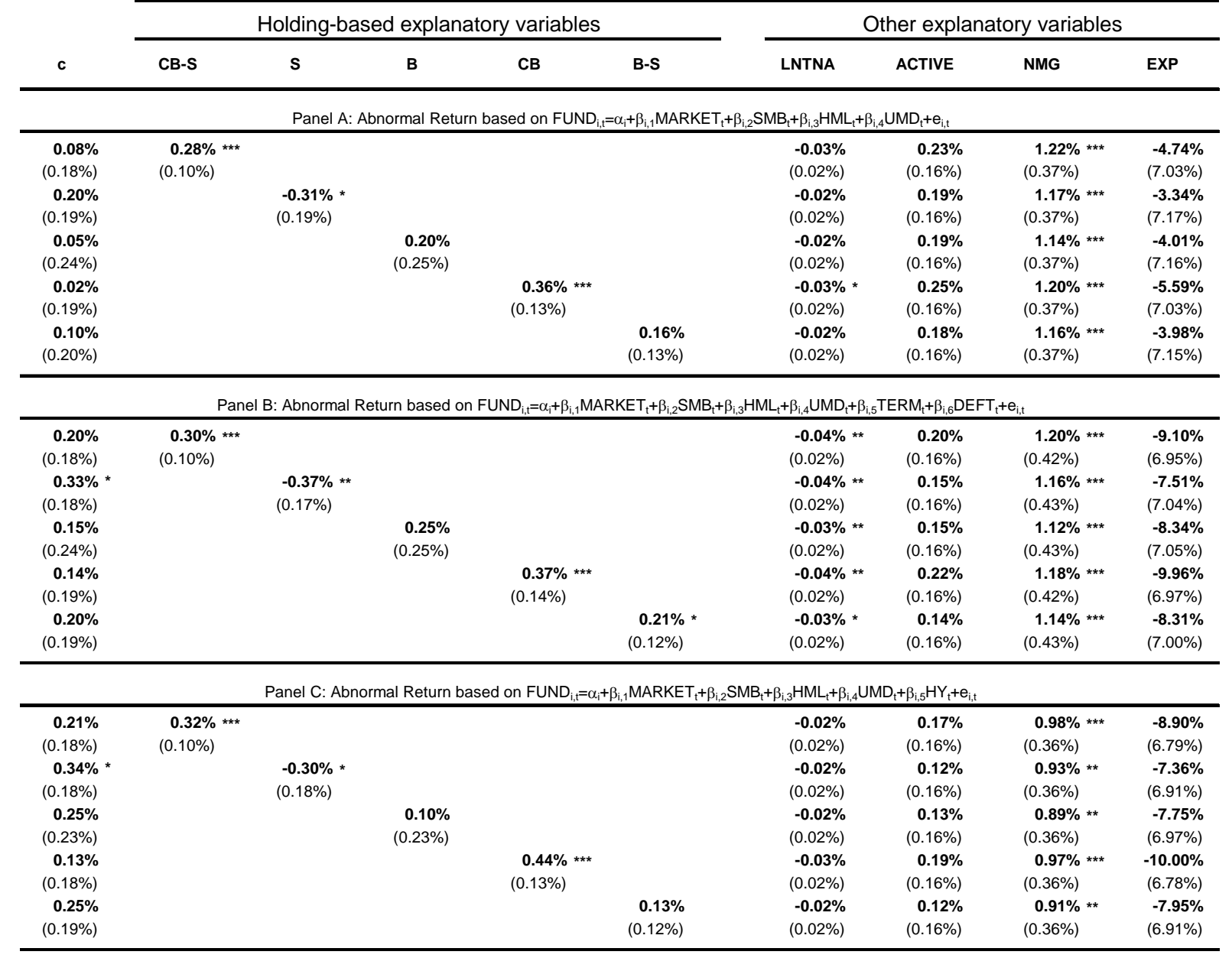


Table VIII-Continued

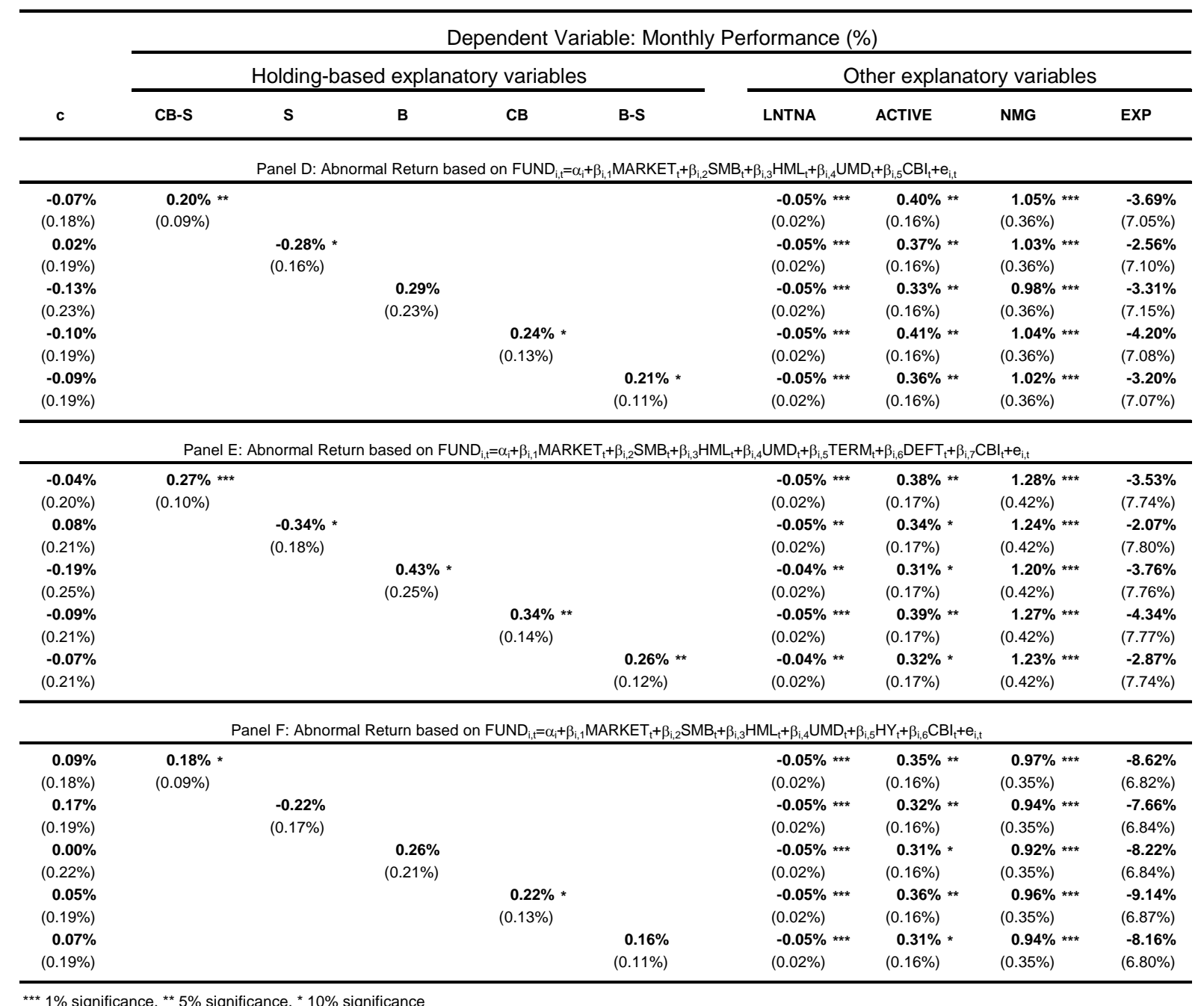




\section{Empirical Analysis with Extended Models}

In this section, we empirically test two additional factors expected to capture variations of CBF returns related to (i) convertible-arbitrage activities and (ii) investment opportunities within the convertible-bond market.

\subsection{Convertible Arbitrage as a Performance Driver}

Convertible arbitrage in its basic form consists of buying undervalued convertible bonds (long position) and hedging away risk related to equity, interest rate, and credit risk by shorting suitable securities (short position). All CBFs can potentially implement the long part of convertible arbitrage by trying to select undervalued convertibles. However, only long-short CBFs are entitled to short stocks and thus implement the short part of convertible arbitrage. Thus, by "convertible arbitrage", we refer either to the combined long-short strategy or to the long part only. Table IX and Table X analyze the factor models with the additional convertible-arbitrage factor. The coefficients of the arbitrage factor show high values and are significant at the $1 \%$ level. Table $\mathrm{X}$ confirms that the coefficients of up to $79 \%$ of all CBFs are significant at the $10 \%$ level in the time-series regressions. The coefficients and significance levels for the other coefficients remain are very similar to the models presented in Section 4 . Moreover, the adjusted $\mathrm{R}^{2}$ and the mean (absolute) pairwise residual correlations are further improved. ${ }^{17}$ Overall, the analysis shows that the convertible-arbitrage factor contributes to explaining CBF returns.

\footnotetext{
${ }^{17}$ The mean absolute pairwise residual correlations can be significantly reduced on the $1 \%$ level.
} 
The purpose of the following multivariate cross-sectional regressions is to verify whether the positive relation between the funds' performance and funds' holdings still exist if the possible existence of a convertible bond arbitrage component is accounted for in the return generating process. In other words, we verify whether the positive relation observed in Subsection 4.3 is driven by a misspecification of the return process or is indeed attributable to specific skills of portfolio managers. 


\section{Table IX}

\section{Comparison of the Extended Models including a Convertible-Arbitrage Factor}

This table reports the coefficients of the panel regression of the general form: $F U N D_{i, t}=\alpha_{i}+\Sigma_{k} \beta_{i j}^{k} \cdot F_{t}^{k}+e_{i, t}$ and $F_{t}^{k}$ are the factors in the performance model and FUND are the monthly excess-returns of convertible bond fund i. The factors of the Carhart (1997) four-factor model are defined as follows: MARKET is the value-weight return on all NYSE, AMEX, and NASDAQ stocks (from CRSP) minus the one-month Treasury bill rate (from Ibbotson Associates), SMB (Small Minus Big) is the average return on three small portfolios minus the average return on three big portfolios, HML (High Minus Low) is the average return on two value portfolios minus the average return on two growth portfolios, UMD (Up Minus Down) is the average return on two high prior return portfolios minus the average return on two low prio return portfolios. The Carhart (1997) factors are from the Kenneth R. French data library on his webpage. Additional factors for generating return processes of stocks and bonds are: TERM is the return of the Lehman US Government Long Bond Index minus the one-month Treasury bill rate. DEFT is the return on the Lehman US Corporate Long Bond Index minus the return of the Lehman US Government Long Bond Index. HY is the return on the Merrill Lynch US High Yield Index. CBI is the return on the Merrill Lynch All US Convertible Bond Index. CBAI is the return on the CSFB/Tremont Convertible Arbitrage Index. All data are provided by Datastream except for the Carhart (1997) factors. Measures are the adjusted $\mathrm{R}^{2}$ (adj. $\mathrm{R}^{2}$ ), the Akaike and the Schwarz Criterions, the mean pairwise residual correlations (MRC), and the mean absolute values of pairwise residual correlations (MAVRC). The sample includes 114 convertible-bond funds from the CRSP Survivor-Bias Free US Mutual Fund Database and spans the period from 1985 to 2004. Panel-corrected standard errors (PCSE) are reported in parenthesis.

Factor Loadings

Additional factors

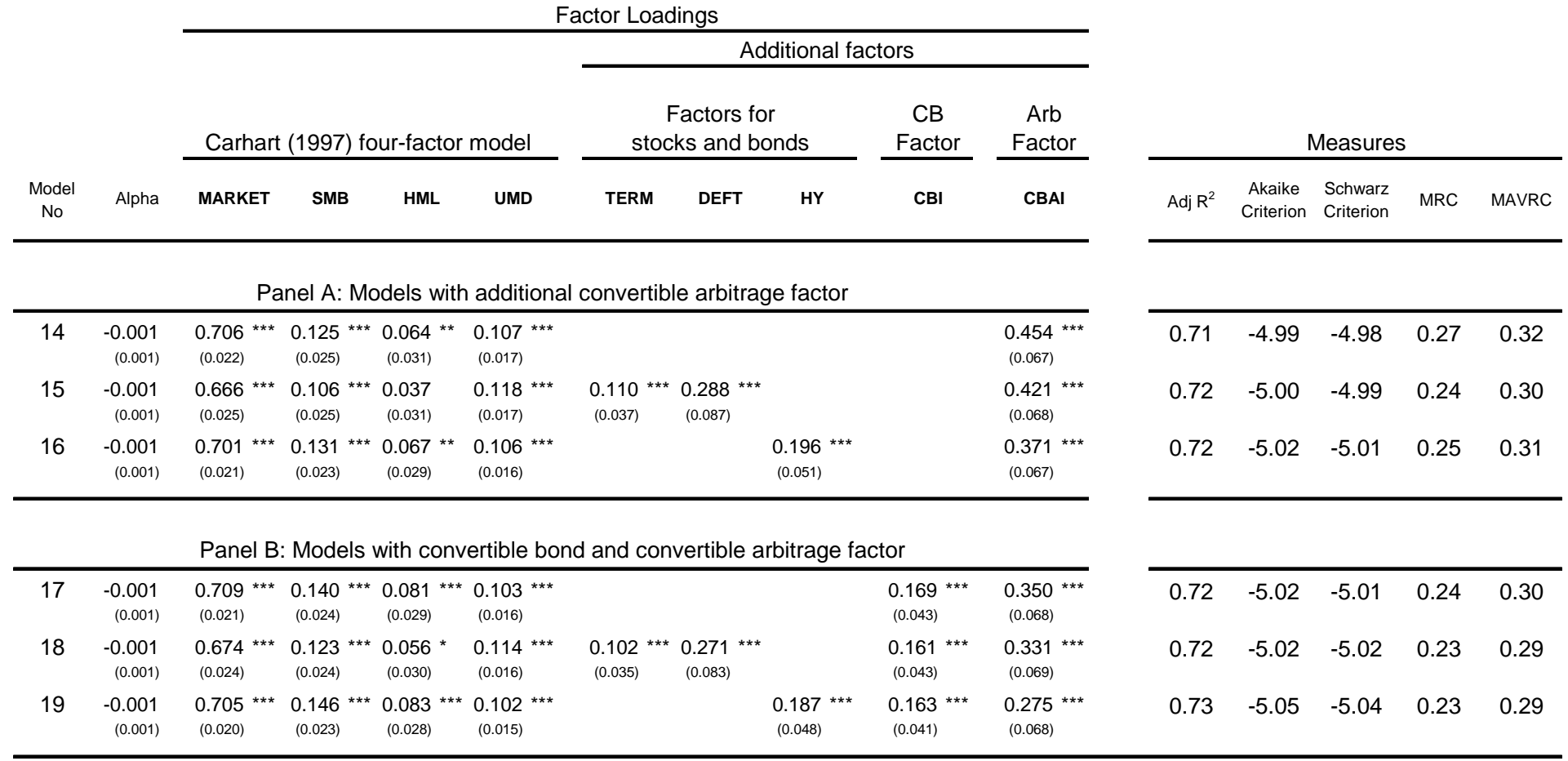

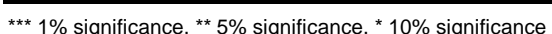




\section{Table X}

\section{Percentage of Significant Time-Series Regression Coefficients for the Extended Models}

This table reports the percentage of time-series regression coefficients that are different from zero at the $10 \%$ level for convertible-bond funds when a time-series regression is run on the excess-returns for each fund against the factors of the selected model (estimated standard errors are adjusted for autocorrelation and heteroskedasticity according to Newey and West, 1987). The time-series regression are of the general form: $\mathrm{FUND}_{\mathrm{i}, \mathrm{t}}=\alpha_{\mathrm{i}}+\Sigma_{\mathrm{k}} \beta_{\mathrm{i}}^{\mathrm{k}} \cdot \mathrm{F}_{\mathrm{t}}^{\mathrm{k}}+\mathrm{e}_{\mathrm{i}, \mathrm{t}}$ and $\mathrm{F}_{\mathrm{t}}^{\mathrm{k}}$ are the factors in the performance model and FUND $\mathrm{F}_{\mathrm{i}, \mathrm{t}}$ are the monthly excess-returns of convertible bond fund $\mathrm{i}$. The factors of the Carhart (1997) four-factor model are as follows: MARKET is the value-weighted return on all NYSE, AMEX, and NASDAQ stocks (from CRSP) minus the one-month Treasury bill rate (from Ibbotson Associates), SMB (Small Minus Big) is the average return on three small portfolios minus the average return on three big portfolios, HML (High Minus Low) is the average return on two value portfolios minus the average return on two growth portfolios, UMD (Up Minus Down) is the average return on two high prior return portfolios minus the average return on two low prior return portfolios. The Carhart (1997) factors are from the Kenneth R. French data library on his webpage. Additional factors for generating return processes of stocks and bonds are: TERM is the return of the Lehman US Government Long Bond Index minus the onemonth Treasury bill rate. DEFT is the return on the Lehman US Corporate Long Bond Index minus the return of the Lehman US Government Long Bond Index. HY is the return on the Merrill Lynch US High Yield Index. CBI is the return on the Merrill Lynch All US Convertible Bond Index. CBAI is the return on the CSFB/Tremont Convertible Arbitrage Index. All data are provided by Datastream except for the Carhart (1997) factors. The sample includes 114 convertiblebond funds from the CRSP Survivor-Bias Free US Mutual Fund Database and spans the period from 1985 to 2004.

\begin{tabular}{|c|c|c|c|c|c|c|c|c|c|c|}
\hline \multirow[b]{3}{*}{$\begin{array}{l}\text { Model } \\
\text { No }\end{array}$} & \multirow[b]{3}{*}{ Alpha } & \multicolumn{9}{|c|}{ Model Factors } \\
\hline & & \multicolumn{4}{|c|}{ Carhart (1997) four-factor model } & \multicolumn{3}{|c|}{$\begin{array}{c}\text { Factor for } \\
\text { stocks and bonds }\end{array}$} & \multirow{2}{*}{$\begin{array}{c}\text { CB } \\
\text { Factor } \\
\mathrm{CBI}\end{array}$} & \multirow{2}{*}{$\begin{array}{c}\begin{array}{c}\text { Arb } \\
\text { Factor }\end{array} \\
\text { CBAI }\end{array}$} \\
\hline & & MARKET & SMB & HML & UMD & TERM & DEFT & $\mathrm{HY}$ & & \\
\hline \multicolumn{11}{|c|}{ Panel A: Models with additional convertible arbitrage factor } \\
\hline 14 & $22 \%$ & $99 \%$ & $67 \%$ & $51 \%$ & $46 \%$ & & & & & $79 \%$ \\
\hline 15 & $21 \%$ & $91 \%$ & $55 \%$ & $38 \%$ & $54 \%$ & $41 \%$ & $31 \%$ & & & $75 \%$ \\
\hline 16 & $24 \%$ & $99 \%$ & $59 \%$ & $44 \%$ & $51 \%$ & & & $58 \%$ & & $71 \%$ \\
\hline \multicolumn{11}{|c|}{ Panel B: Models with convertible bond and convertible arbitrage factor } \\
\hline 17 & $17 \%$ & $96 \%$ & $56 \%$ & $50 \%$ & $51 \%$ & & & & $23 \%$ & $44 \%$ \\
\hline 18 & $16 \%$ & $90 \%$ & $50 \%$ & $35 \%$ & $56 \%$ & $45 \%$ & $45 \%$ & & $17 \%$ & $42 \%$ \\
\hline 19 & $16 \%$ & $91 \%$ & $52 \%$ & $40 \%$ & $51 \%$ & & & $40 \%$ & $22 \%$ & $45 \%$ \\
\hline
\end{tabular}




\section{Full Sample}

As in Section 4, we analyze whether the performance of convertible-bond funds is related to fund characteristics, determined by the six CBAI-extended models. Table XI shows the results of the multivariate cross-sectional analysis. Strikingly, no significant relation can be observed between the performance of convertible-bond funds and the holding-based variables. By comparing the results in Table VIII and Table XI, it can immediately be seen that the positive relation between funds' performance and the percentage invested in convertible bonds minus the percentage invested in stocks is, to a great part, attributable to convertible arbitrage related activities. The return component induced by convertible bond arbitrage is not captured by any of the models presented in Section 4. In the next subsections, we show that the important results just presented are very robust and do not depend on the specific time period and performance definition used for calculations. 
Table XI

Multivariate Panel Regression Evidence for the Extended Models

This table reports the coefficients of the monthly panel and multivariate cross-sectional regression of the general form: $\mathrm{PERF}_{\mathrm{i}, t}=\mathrm{c}+\chi_{1} \mathrm{HV}_{\mathrm{i}, \mathrm{t}-\mathrm{e}}$ $+\chi_{2}$ LNTNA $_{\mathrm{i}, \mathrm{t}-1}+\chi_{3} \mathrm{ACTIVE}_{\mathrm{it-1}-1}+\chi_{4} \mathrm{NMG}_{\mathrm{i}, \mathrm{t}-1}+\chi_{5} \mathrm{EXP}_{\mathrm{i}, \mathrm{t}-1}+\varepsilon_{\mathrm{i}, \mathrm{t}}$ where HV stands for the holding-based variables: CB-S, S, B, CB, and B-S. The dependent variable, PERF, measures the monthly performance (abnormal return) using different performance models (Panel A to Panel $\mathrm{F}$ ) based on 36 months of lagged data to determine the betas in the performance models. The abnormal returns are calculated as follows: $P E R F_{i, t}=F U N D_{i, t}-\Sigma_{k} \beta_{i, t-1}^{k} F_{t}^{k}$ and $F^{k}$ are the factors in the performance model. The holding-based variables are the asset compositions in PERF $F_{i, t}=F U N D_{i, t}-\Sigma_{k} \beta_{i, t-1}^{k} F_{t}^{k}$ and $F_{t}^{k}$ are the factors in the performance model. The holding-based variables are the asset compositions in
percentages invested in convertible bonds (CB), stocks (S), bonds inclusive convertible bonds (B), convertible bonds minus stocks (CB-S) percentages invested in convertible bonds (CB), stocks (S), bonds inclusive convertible bonds (B), convertible bonds minus stocks (CB-S)
and bonds inclusive convertible bonds minus stocks (B-S), respectively. We denote the natural logarithm of total net assets by LNTNA, the new money growth per month by NMG and the expense ration by EXP. The variable ACTIVE is a dummy variable that is one if the convertible bond fund is active and zero otherwise. Mitigating potential endogeneity problems, we lag all explanatory variables by one month. The sample includes convertible-bond funds from the CRSP Survivor-Bias Free US Mutual Fund Database and spans the period from 1995 to 2004 (including the data used for calculating the abnormal returns). Panel-corrected standard errors (PCSE) are reported in parenthesis.

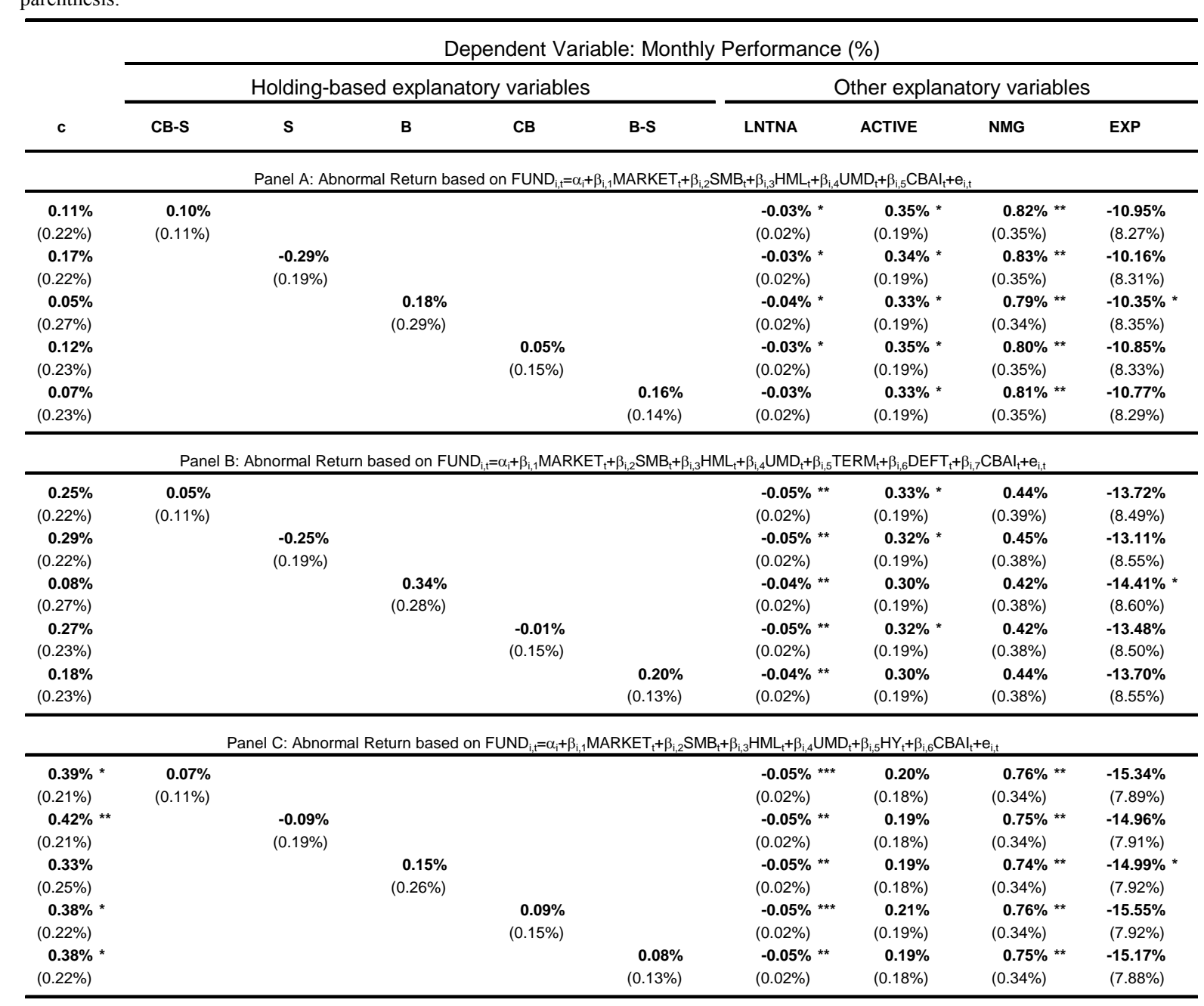


Table XI-Continued

\begin{tabular}{|c|c|c|c|c|c|c|c|c|c|}
\hline \multirow[b]{3}{*}{ c } & \multicolumn{9}{|c|}{ Dependent Variable: Monthly Performance (\%) } \\
\hline & \multicolumn{5}{|c|}{ Holding-based explanatory variables } & \multicolumn{4}{|c|}{ Other explanatory variables } \\
\hline & CB-S & s & B & CB & B-S & LNTNA & ACTIVE & NMG & EXP \\
\hline \multicolumn{10}{|c|}{ 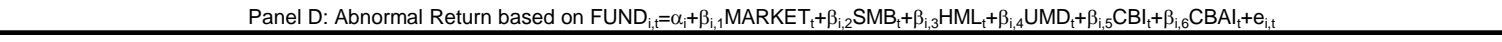 } \\
\hline $\begin{array}{r}0.06 \% \\
(0.22 \%)\end{array}$ & $\begin{array}{r}\mathbf{0 . 0 4 \%} \\
(0.11 \%)\end{array}$ & & \multirow{7}{*}{$\begin{array}{r}0.27 \% \\
(0.26 \%)\end{array}$} & \multirow{7}{*}{$\begin{array}{r}-0.04 \% \\
(0.15 \%)\end{array}$} & \multirow{7}{*}{$\begin{array}{r}0.18 \% \\
(0.13 \%)\end{array}$} & $\begin{array}{l}-0.06 \% * * * \\
(0.02 \%)\end{array}$ & $\begin{array}{c}0.47 \% \text { ** } \\
(0.19 \%)\end{array}$ & $\begin{array}{c}\mathbf{0 . 7 2 \%} \text { ** } \\
(0.34 \%)\end{array}$ & $\begin{array}{r}-12.71 \% \\
(7.95 \%)\end{array}$ \\
\hline $0.10 \%$ & & $-0.25 \%$ & & & & $-0.06 \%$ *** & $0.46 \%$ ** & $0.73 \%$ ** & $-12.16 \%$ \\
\hline$(0.21 \%)$ & & $(0.18 \%)$ & & & & $(0.02 \%)$ & $(0.19 \%)$ & $(0.34 \%)$ & $(7.99 \%)$ \\
\hline $\begin{array}{r}-0.08 \% \\
(0.25 \%)\end{array}$ & & & & & & $\begin{array}{l}-0.06 \% \text { *** } \\
(0.02 \%)\end{array}$ & $\begin{array}{l}0.45 \% \text { ** } \\
(0.19 \%)\end{array}$ & $\begin{array}{l}0.71 \% \text { ** } \\
(0.34 \%)\end{array}$ & $\begin{array}{l}-12.80 \% \\
(8.01 \%)\end{array}$ \\
\hline $\begin{array}{r}0.08 \% \\
(0.22 \%)\end{array}$ & & & & & & $\begin{array}{l}-0.06 \% \text { *** } \\
(0.02 \%)\end{array}$ & $\begin{array}{l}0.46 \% \text { ** } \\
(0.19 \%)\end{array}$ & $\begin{array}{l}0.70 \% \text { ** } \\
(0.34 \%)\end{array}$ & $\begin{array}{r}-12.37 \% \\
(7.98 \%)\end{array}$ \\
\hline$-0.01 \%$ & & & & & & $-0.06 \% * * *$ & $0.45 \%$ ** & $0.73 \%$ ** & $-12.73 \%$ \\
\hline$(0.22 \%)$ & & & & & & $(0.02 \%)$ & $(0.19 \%)$ & $(0.34 \%)$ & $(7.96 \%)$ \\
\hline \multicolumn{10}{|c|}{ 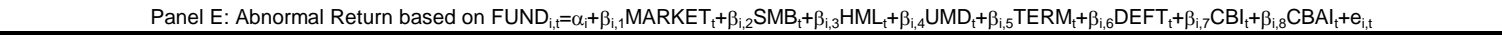 } \\
\hline$-0.10 \%$ & $-0.10 \%$ & & \multirow{10}{*}{$\begin{array}{r}0.02 \% \\
(0.27 \%)\end{array}$} & & \multirow{10}{*}{$\begin{array}{r}0.04 \% \\
(0.13 \%)\end{array}$} & \multirow{10}{*}{$\begin{array}{l}-0.05 \% \text { ***} \\
(0.02 \%) \\
-0.05 \% \text { ***} \\
(0.02 \%) \\
-0.05 \% \text { ***} \\
(0.02 \%) \\
-0.05 \% \text { *** } \\
(0.02 \%) \\
-0.05 \% \text { *** } \\
(0.02 \%)\end{array}$} & \multirow{10}{*}{ 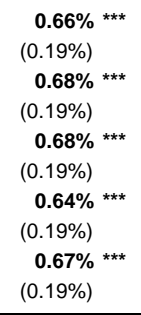 } & $0.42 \%$ & \multirow{10}{*}{$\begin{array}{c}-11.09 \% \\
(8.16 \%) \\
-11.27 \% \\
(8.22 \%) \\
-11.49 \% \\
-(8.27 \%) \\
-10.31 \% \\
-(8.19 \%) \\
-11.46 \%)\end{array}$} \\
\hline$(0.22 \%)$ & $(0.11 \%)$ & & & & & & & $(0.38 \%)$ & \\
\hline$-0.12 \%$ & & $-0.09 \%$ & & & & & & $0.47 \%$ & \\
\hline$(0.22 \%)$ & & $(0.18 \%)$ & & & & & & $(0.37 \%)$ & \\
\hline$-0.14 \%$ & & & & & & & & $0.45 \%$ & \\
\hline$(0.26 \%)$ & & & & & & & & $(0.37 \%)$ & \\
\hline$-0.04 \%$ & & & & $-0.22 \%$ & & & & $0.41 \%$ & \\
\hline$(0.23 \%)$ & & & & $(0.15 \%$ & & & & $(0.38 \%)$ & \\
\hline$-0.15 \%$ & & & & & & & & $0.46 \%$ & \\
\hline$(0.22 \%)$ & & & & & & & & $(0.37 \%)$ & \\
\hline \multicolumn{10}{|c|}{ 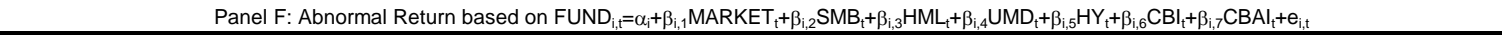 } \\
\hline $0.14 \%$ & $0.07 \%$ & & & & & $-0.06 \%$ ** & $0.38 \%$ ** & $0.72 \%$ ** & $-11.54 \%$ \\
\hline$(0.21 \%)$ & $(0.11 \%)$ & & & & & $(0.02 \%)$ & $(0.18 \%)$ & $(0.35 \%)$ & $(7.85 \%)$ \\
\hline $0.18 \%$ & & $-0.15 \%$ & & & & $-0.05 \%$ ** & $0.36 \%$ ** & $0.72 \%$ ** & $-11.05 \%$ \\
\hline$(0.21 \%)$ & & $(0.19 \%)$ & & & & $(0.02 \%)$ & $(0.18 \%)$ & $(0.35 \%)$ & $(7.88 \%)$ \\
\hline $0.02 \%$ & & & $0.28 \%$ & & & $-0.05 \%$ * & $0.35 \%$ * & $0.70 \%$ ** & $-12.02 \%$ \\
\hline$(0.25 \%)$ & & & $(0.25 \%)$ & & & $(0.02 \%)$ & $(0.18 \%)$ & $(0.35 \%)$ & (7.88\%) \\
\hline $0.14 \%$ & & & & $0.06 \%$ & & $-0.06 \% * \star *$ & $0.38 \%$ ** & $0.71 \%$ ** & $-11.60 \%$ \\
\hline$(0.22 \%)$ & & & & $(0.15 \%$ & & $(0.02 \%)$ & $(0.18 \%)$ & $(0.35 \%)$ & $(7.88 \%)$ \\
\hline $0.10 \%$ & & & & & $0.14 \%$ & $-0.05 \% * \star *$ & $0.35 \%$ ** & $0.72 \%$ ** & $-11.43 \%$ \\
\hline$(0.22 \%)$ & & & & & $(0.13 \%)$ & $(0.02 \%)$ & $(0.18 \%)$ & $(0.35 \%)$ & $(7.84 \%)$ \\
\hline
\end{tabular}




\section{Sub Periods}

In Table XII, we examine the relation between the explanatory variables and the fund performance for two sub-samples: 1999-2001 and 2002-2004. Table XII compares the result of one of the models in Section 4 (Panel A and Panel C) with its extended counterpart (Panel B and Panel D). Panel A and Panel B refer to the period 1999 2001 (the period between 1996 and 1998 is used for calculating the abnormal returns). Panel C and Panel D of Table XII examine the sub-period 2002 - 2004. Again, the period between 1999 and 2001 is used for calculating abnormal returns. The results of this analysis confirm that the relation between the holding-based measure $\mathrm{CB}-\mathrm{S}$ and the fund performance disappears as soon as a convertible arbitrage factor is included in the factor model. We obtain similar results (not reported) when testing other pairs of models from Section 4 with their CBAIaugmented counterparts.

\section{Alternative Risk Adjustments}

As CBF portfolios typically deviate from the market portfolio, they are exposed to idiosyncratic risk. To take into account the different amounts of unique risk across our sample funds, we employ the appraisal ratio of Treynor and Black (1973) as alternative measure for the abnormal performance of a fund. Table XIII reports the coefficients of the monthly panel and multivariate cross-sectional regression of the general form:

$$
\text { TBAR }_{i, t}=c+\chi_{1} \mathrm{HV}_{\mathrm{i}, \mathrm{t}-1}+\chi_{2} \mathrm{LNTNA}_{\mathrm{i}, \mathrm{t}-1}+\chi_{3} \mathrm{ACTIVE}_{\mathrm{i}, \mathrm{t}-1}+\chi_{4} \mathrm{NMG}_{\mathrm{i}, \mathrm{t}-1}+\chi_{5} \mathrm{EXP}_{\mathrm{i}, \mathrm{t}-1}+\varepsilon_{\mathrm{i}, \mathrm{t}}
$$


HV stands for the holding-based variables: CB-S, S, B, CB and B-S. The dependent variable, TBAR measures the monthly performance (Appraisal Ratio of Treynor and Black, 1973) using different performance models (Panel A to Panel F) based on three years of lagged data to determine the betas in the performance models. The appraisal ratio is calculated by dividing the abnormal return by the standard deviation of the residuals from the performance model. The abnormal returns are calculated as follows: PERF $F_{\mathrm{i}, \mathrm{t}}=\mathrm{FUND}_{\mathrm{i}, \mathrm{t}}-\Sigma_{\mathrm{k}} \beta_{\mathrm{i}, \mathrm{t}-1}^{\mathrm{k}} \mathrm{F}_{\mathrm{t}}^{\mathrm{k}}$. $\mathrm{F}_{\mathrm{t}}^{\mathrm{k}}$ are the factors in the performance model. The empirical results suggest that the performance is not driven by the amount of idiosyncratic risk. We obtain similar results (not reported) when testing other pairs of models with their CBAI-extended counterparts.

The main results of this section can be summarized as follows: the multivariate cross-sectional analysis applied to all models presented in Section 4 show a strong relationship between the holding-based parameter CB-S (percentage invested in convertibles minus percentage invested in stocks) and the performance of individual convertible-bond funds. However, this positive relationship disappears if the models are extended by a convertible arbitrage factor. Multivariate cross-sectional analyses performed on sub-periods and by accounting for idiosyncratic risk underpin the robustness of the results. 
Table XII

\section{Multivariate Panel Regression Evidence: Sub-Periods}

This table reports the coefficients of the monthly panel and multivariate cross-sectional regression of the general form: $\mathrm{PERF}_{\mathrm{i}, \mathrm{t}}=\mathrm{c}+\chi_{1} \mathrm{HV}_{\mathrm{i}, \mathrm{t}}$ ${ }_{1}+\chi_{2}$ LNTNA $_{\mathrm{i},-1-1}+\chi_{3} \mathrm{ACTIVE}_{\mathrm{i},-1}+\chi_{4} \mathrm{NMG}_{\mathrm{i}, \mathrm{t}-1}+\chi_{5} \mathrm{EXP}_{\mathrm{i}, \mathrm{t}-1}+\varepsilon_{\mathrm{i}, \mathrm{t}}$ where HV stands for the holding-based variables: CB-S, S, B, CB and B-S. The dependent variable, PERF, measures the monthly performance (abnormal return) using different performance models (Panel A to Panel F) based on 36 month of lagged data to determine the betas in the performance models. The abnormal returns are calculated as follows: $\mathrm{PERF}_{\mathrm{i}, \mathrm{t}}=\mathrm{FUND}_{\mathrm{i}, \mathrm{t}}-\Sigma_{\mathrm{k}} \beta_{\mathrm{i}, t-1}^{\mathrm{k}} \mathrm{F}_{\mathrm{t}}^{\mathrm{k}}$ and $\mathrm{F}_{\mathrm{t}}^{\mathrm{k}}$ are the factors in the performance model. The holding-based variables are the asset compositions in percentages invested in convertible bonds (CB), stocks (S), bonds inclusive convertible bonds (B), convertible bonds minus stocks (CB-S) and bonds inclusive convertible bonds minus stocks (B-S), respectively. We denote the natural logarithm of total net assets by LNTNA, the new money growth per month by NMG and the expense ration by EXP. The variable ACTIVE is a dummy variable and is one if the convertible bond fund is active and zero otherwise. Mitigating potential endogeneity problems, we lag all explanatory variables by one month. The sample includes convertible-bond funds from the CRSP Survivor-Bias Free US Mutual Fund Database and spans the period from 1996 to 2001 (Panel A and Panel B) and 1999 to 2004 (Panel C and Panel D) - including the data used for calculating the abnormal returns. Panel-corrected standard errors (PCSE) are reported in parenthesis.

\begin{tabular}{|c|c|c|c|c|c|c|c|c|c|}
\hline \multirow[b]{3}{*}{ c } & \multicolumn{9}{|c|}{1999 - 2001. Dependent Variable: Monthly Performance (\%) } \\
\hline & \multicolumn{5}{|c|}{ Holding-based explanatory variables } & \multicolumn{4}{|c|}{ Other explanatory variables } \\
\hline & CB-S & $\mathrm{s}$ & B & $\mathrm{CB}$ & B-S & LNTNA & ACTIVE & NMG & EXP \\
\hline \multicolumn{10}{|c|}{ Panel A: Abnormal Return 1999-2001 based on FUND $\mathrm{FU}_{i, 1}=\alpha_{\mathrm{i}}+\beta_{\mathrm{i}, 1} \mathrm{MARKET}_{\mathrm{t}}+\beta_{\mathrm{i}, 2} \mathrm{SMB}_{\mathrm{t}}+\beta_{\mathrm{i}, 3} \mathrm{HML} \mathrm{L}_{\mathrm{t}}+\beta_{\mathrm{i}, 4} \mathrm{UMD}_{\mathrm{t}}+\beta_{i, 5} \mathrm{TERM}_{\mathrm{t}}+\beta_{\mathrm{i}, 6} \mathrm{DEFT}_{\mathrm{t}}+\beta_{\mathrm{i}, 7} \mathrm{CBB}_{\mathrm{t}}+\mathrm{e}_{\mathrm{i}, \mathrm{t}}$} \\
\hline$-0.22 \%$ & $0.53 \%$ ** & & & & & $-0.06 \%$ & $0.54 \%$ ** & $2.10 \%$ & $-7.61 \%$ \\
\hline$(0.32 \%)$ & $(0.22 \%)$ & & & & & $(0.04 \%)$ & $(0.23 \%)$ & $(0.58 \%)$ & $(14.93 \%)$ \\
\hline $0.05 \%$ & & $-0.87 \%$ & & & & $-0.06 \%$ & $0.50 \%$ ** & $2.13 \%$ * & $-5.32 \%$ \\
\hline$(0.34 \%)$ & & $(0.53 \%)$ & & & & $(0.04 \%)$ & $(0.23 \%)$ & $(0.59 \%)$ & (15.05\%) \\
\hline$-0.49 \%$ & & & $0.76 \%$ * & & & $-0.05 \%$ & $0.46 \%$ ** & $2.04 \%$ * & $-4.86 \%$ \\
\hline$(0.40 \%)$ & & & $(0.46 \%)$ & & & $(0.04 \%)$ & $(0.22 \%)$ & $(0.59 \%)$ & (14.58\%) \\
\hline$-0.41 \%$ & & & & $0.76 \%$ ** & & $-0.06 \%$ & $0.56 \%$ ** & $2.07 \%$ *** & $-7.96 \%$ \\
\hline$(0.33 \%)$ & & & & $(0.30 \%)$ & & $(0.04 \%)$ & $(0.23 \%)$ & $(0.58 \%)$ & $(14.84 \%)$ \\
\hline$-0.28 \%$ & & & & & $0.51 \%$ * & $-0.06 \%$ & $0.48 \%$ ** & $2.08 \%$ *** & $-5.40 \%$ \\
\hline$(0.33 \%)$ & & & & & $(0.27 \%)$ & $(0.04 \%)$ & $(0.23 \%)$ & $(0.59 \%)$ & $(14.74 \%)$ \\
\hline \multicolumn{10}{|c|}{ 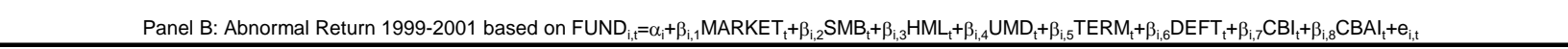 } \\
\hline$-0.53 \%$ & $0.06 \%$ & & & & & $-0.04 \%$ & $0.92 \%$ *** & $0.97 \%$ * & $-17.21 \%$ \\
\hline$(0.34 \%)$ & $(0.23 \%)$ & & & & & $(0.04 \%)$ & $(0.25 \%)$ & $(0.51 \%)$ & $(15.99 \%)$ \\
\hline$-0.51 \%$ & & $-0.02 \%$ & & & & $-0.04 \%$ & $0.91 \%$ * & $0.97 \%$ * & $-16.82 \%$ \\
\hline$(0.36 \%)$ & & $(0.54 \%)$ & & & & $(0.04 \%)$ & $(0.25 \%)$ & $(0.52 \%)$ & (15.91\%) \\
\hline$-0.21 \%$ & & & $-0.59 \%$ & & & $-0.04 \%$ & $0.93 \%$ & $1.04 \%$ ** & $-15.95 \%$ \\
\hline$(0.43 \%)$ & & & $(0.47 \%)$ & & & $(0.04 \%)$ & $(0.25 \%)$ & $(0.52 \%)$ & (15.91\%) \\
\hline$-0.56 \%$ & & & & $0.11 \%$ & & $-0.04 \%$ & $0.92 \%$ & $0.97 \%$ * & $-17.38 \%$ \\
\hline$(0.36 \%)$ & & & & $(0.31 \%)$ & & $(0.04 \%)$ & $(0.25 \%)$ & $(0.51 \%)$ & $(15.95 \%)$ \\
\hline$-0.44 \%$ & & & & & $-0.21 \%$ & $-0.04 \%$ & $0.91 \%$ *** & $0.99 \%$ * & $-16.09 \%$ \\
\hline$(0.35 \%)$ & & & & & $(0.28 \%)$ & $(0.04 \%)$ & $(0.25 \%)$ & $(0.51 \%)$ & (15.88\%) \\
\hline
\end{tabular}


Table XII-Continued

2002 - 2004. Dependent Variable: Monthly Performance (\%)

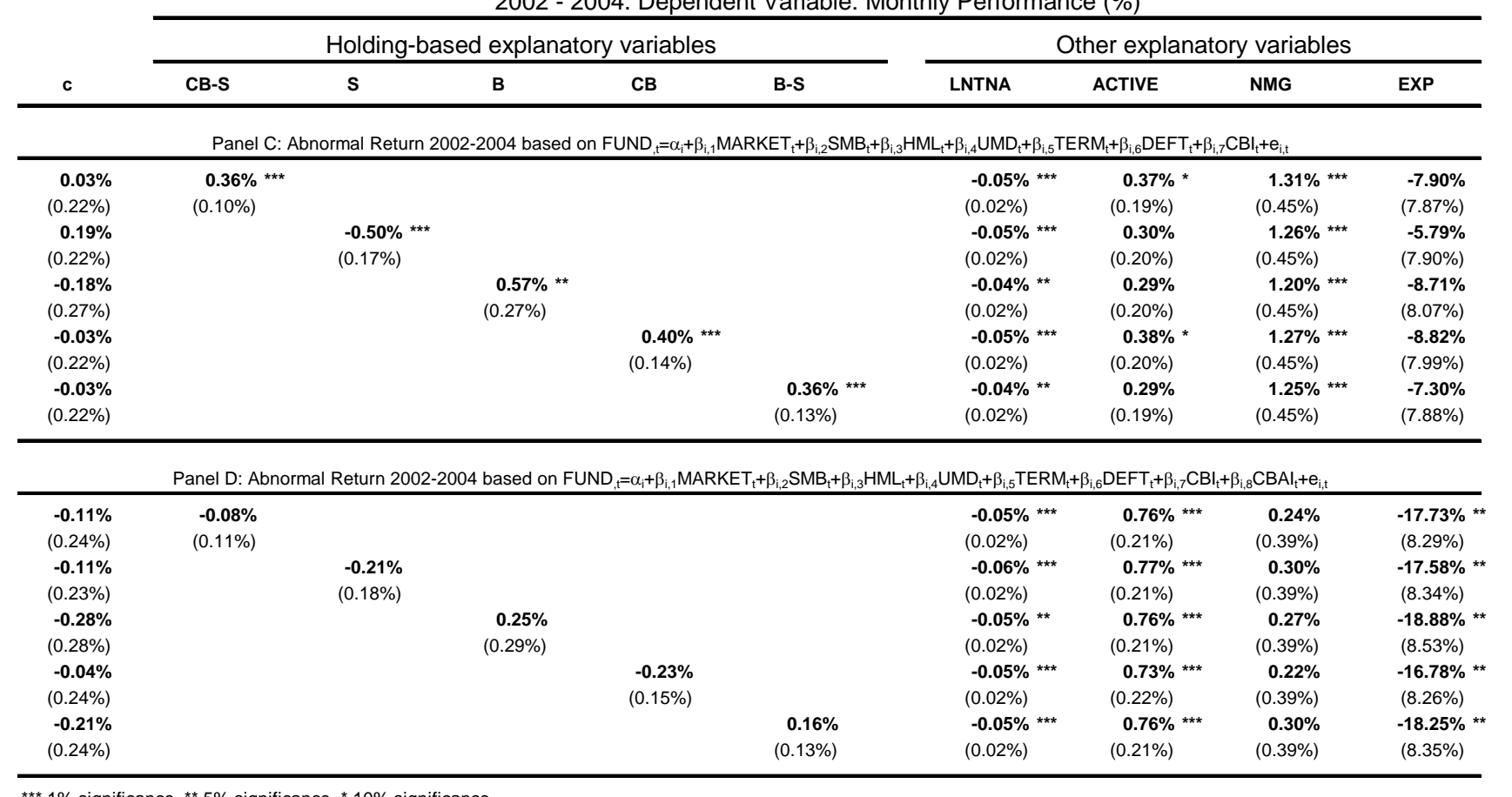

${ }^{* \star *} 1 \%$ significance, ${ }^{*} 5 \%$ significance, ${ }^{*} 10 \%$ significance 


\section{Table XIII}

\section{Multivariate Panel Regression Evidence: Alternative Risk Adjustment}

This table reports the coefficients of the monthly panel and multivariate cross-sectional regression of the general form: $\mathrm{TBAR}_{\mathrm{i}, \mathrm{t}}=\mathrm{c}+\chi_{1} \mathrm{HV}_{\mathrm{i}, \mathrm{t}-1}+\chi_{2} \mathrm{LNTNA}_{\mathrm{i}, \mathrm{t}-1}+\chi_{3} \mathrm{ACTIVE}_{\mathrm{i}, \mathrm{t}-1}+\chi_{4} \mathrm{NMG}_{\mathrm{i}, \mathrm{t}-1}+\chi_{5} \mathrm{EXP}_{\mathrm{i}, \mathrm{t}-1}+\varepsilon_{\mathrm{i}, \mathrm{t}}$ where HV stands for the holding-based variables: CB-S, S, B, CB and B-S. The dependent variable, TBAR measures the monthly performance (Appraisal Ratio of Treynor and Black 1973) using different performance models (Panel A to Panel F) based on 36 months of lagged data to determine the betas in the performance models. The appraisal ratio is calculated by dividing the abnormal return by the standard deviation of the residuals from the performance model. The abnormal returns are calculated as follows: $P E R F_{i, t}=F_{U N D},{ }_{i, t} \beta^{k}{ }_{i, t-1} F_{t}^{k}$ and $F_{t}^{k}$ are the factors in the performance model. The holding-based variables are the asset compositions in percentage invested in convertible bonds (CB), stocks (S), bonds inclusive convertible bonds (B), convertible bonds minus stocks (CB-S) and bonds inclusive convertible bonds minus stocks (B-S), respectively. We denote the natural logarithm of total net assets by LNTNA, the new money growth per month by NMG and the expense ration by EXP. The variable ACTIVE is a dummy variable and is one if the convertible bond fund is active and zero otherwise. Mitigating potential endogeneity problems, we lag all explanatory variables by one month. The sample includes convertible-bond funds from the CRSP Survivor-Bias Free US Mutual Fund Database and spans the period from 1995 to 2004 (including the data used for calculating the abnormal returns). Panel-corrected standard errors (PCSE) are reported in parenthesis.

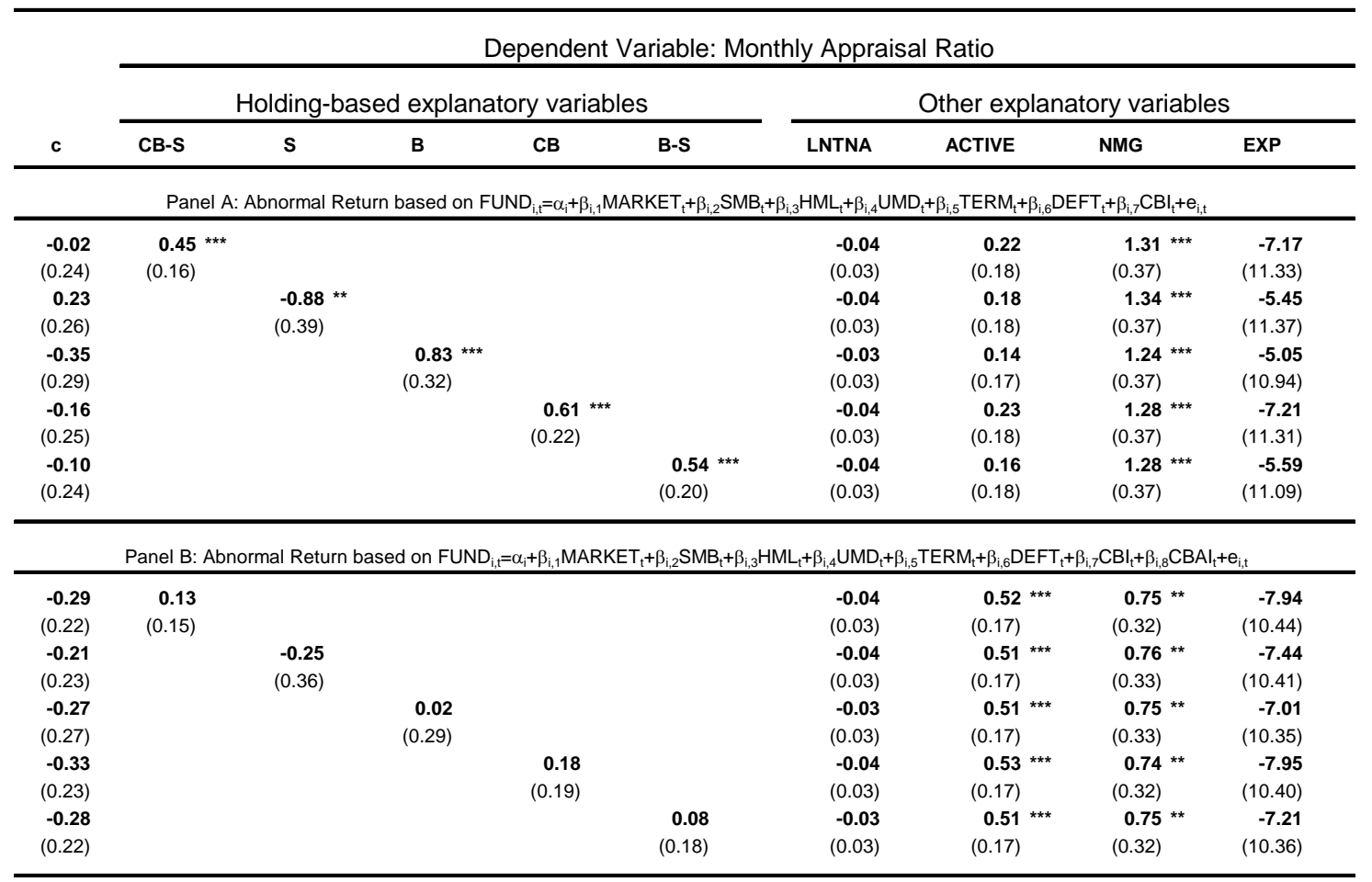

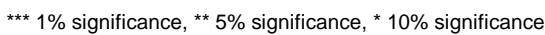




\subsection{Supply and Demand Factor as a Performance Driver}

In this subsection, we include the supply-demand factor (SD) defined in Section 3.4. We consider this factor for two reasons. First, in a recent paper, Agarwal et al. (2006) claim that convertible-arbitrage hedge funds are important players in the convertible-bond market. They further show that abnormal returns of convertible-arbitrage hedge funds (CAHFs) cease to be positive once the supply-demand factor SD - measuring the investment opportunities available in the convertible-bond market - is included in the regression model. Second, the results in the previous subsection indicate that the return process of $\mathrm{CBF}$ s is affected by the convertible-arbitrage factor (CBAI). These two findings lead us to the hypothesis that SD might explain an important portion of CBF returns.

Thus, similar to the work of Agarwal et al. (2006), we include SD in our factor models. We follow recent work by Fung and Hsieh (2004), Fung et al. (2005), and Agarwal et al. (2006) and account for the structural break in hedge fund returns related to the systemic liquidity squeeze on CAHFs following the LTCM crisis of 1998 by differentiating between the pre- and the post-LTCM period. 


\section{Table XIV \\ Models including a Supply Demand Factor}

This table reports the coefficients of the panel regression of the general form: $\mathrm{FUND}_{\mathrm{i}, \mathrm{t}}=\alpha_{\mathrm{i}}+\Sigma_{\mathrm{k}} \beta^{\mathrm{k}}{ }_{\mathrm{i}} \cdot \mathrm{F}^{\mathrm{k}}{ }_{\mathrm{t}}+\mathrm{e}_{\mathrm{i}, \mathrm{t}}$ and $\mathrm{F}^{\mathrm{k}}{ }_{\mathrm{t}}$ are the factors in the performance model and FUND ${ }_{i, t}$ are the monthly excess-returns of convertible bond fund i. The factors of the Carhart (1997) fourfactor model are defined as follows: MARKET is the value-weighted return on all NYSE, AMEX, and NASDAQ stocks (from CRSP) minus the one-month Treasury bill rate (from Ibbotson Associates), SMB (Small Minus Big) is the average return on three small portfolios minus the average return on three big portfolios, HML (High Minus Low) is the average return on two value portfolios minus the average return on two growth portfolios, UMD (Up Minus Down) is the average return on two high prior return portfolios minus the average return on two low prior return portfolios. The Carhart (1997) factors are from the Kenneth R. French data library on his webpage. SD is the supply demand factor. CBAI is the return on the CSFB/Tremont Convertible Arbitrage Index. All data are provided by Datastream except for the Carhart (1997) factors. Measures are the adjusted $\mathrm{R}^{2}$ (adj. $\mathrm{R}^{2}$ ), the Akaike and the Schwarz Criterions. The sample includes 114 convertible-bond funds from the CRSP Survivor-Bias Free US Mutual Fund Database and spans the period from 1985 to 2004 .

Panel A: Models with an additional SD-Factor

\begin{tabular}{|c|c|c|c|c|c|c|c|c|c|c|}
\hline \multirow[b]{2}{*}{ Period } & \multirow[b]{2}{*}{ Alpha } & \multicolumn{5}{|c|}{ Factor Loadings } & \multirow[b]{2}{*}{ CBAI } & \multirow[b]{2}{*}{$\operatorname{Adj} R^{2}$} & \multirow[b]{2}{*}{$\begin{array}{l}\text { Akaike } \\
\text { Criterion }\end{array}$} & \multirow[b]{2}{*}{$\begin{array}{l}\text { Schwarz } \\
\text { Criterion }\end{array}$} \\
\hline & & MARKET & SMB & HML & UMD & SD & & & & \\
\hline $\begin{array}{l}\text { Pre-LTCM } \\
\text { 1/1994-6/1998 }\end{array}$ & $-0.004 * * *$ & 0.646 *** & 0.227 *** & 0.148 *** & 0.033 & 0.237 *** & & 0.77 & -6.17 & -6.15 \\
\hline $\begin{array}{l}\text { Post-LTCM } \\
3 / 1999-12 / 2004\end{array}$ & 0.004 * & 0.744 *** & 0.074 ** & -0.002 & 0.125 *** & 0.433 * & & 0.68 & -4.71 & -4.70 \\
\hline $\begin{array}{l}\text { Entire Period } \\
\text { 1/1994-12/2004 }\end{array}$ & -0.001 & $0.700 * \star *$ & $0.119 * * *$ & 0.058 * & $0.104 * \star *$ & 0.062 & & 0.69 & -4.91 & -4.90 \\
\hline
\end{tabular}

Panel B: Models with and without a SD- and CBAI-Factor in the pre-LTCM period 1/1994 - 6/1998

\begin{tabular}{|c|c|c|c|c|c|c|c|c|c|c|}
\hline $\begin{array}{l}\text { Pre-LTCM } \\
1 / 1994-6 / 1998\end{array}$ & -0.003 *** & 0.648 *** & 0.247 *** & 0.157 *** & 0.029 & & & 0.76 & -6.15 & -6.14 \\
\hline $\begin{array}{l}\text { Pre-LTCM } \\
\text { 1/1994-6/1998 }\end{array}$ & -0.004 *** & 0.646 *** & 0.227 *** & 0.148 *** & 0.033 & $0.237^{* \star \star}$ & & 0.77 & -6.17 & -6.15 \\
\hline $\begin{array}{l}\text { Pre-LTCM } \\
\text { 1/1994-6/1998 }\end{array}$ & $-0.003 * \star * *$ & 0.630 *** & 0.220 *** & 0.141 *** & 0.023 & & 0.275 *** & 0.77 & -6.20 & -6.18 \\
\hline $\begin{array}{l}\text { Pre-LTCM } \\
\text { 1/1994-6/1998 }\end{array}$ & -0.003 *** & $0.629 * \star \star$ & $0.210 * \star *$ & $0.134 * \star \star *$ & 0.025 & 0.267 *** & 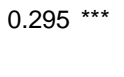 & 0.78 & -6.20 & -6.18 \\
\hline
\end{tabular}

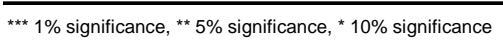


The results of the panel regressions in Table XIV show that the additional SD-factor is highly significant in the pre-LTCM period. Interestingly, its inclusion does not influence the significance level of the convertible-arbitrage factor (CBAI). Thus, the returns of CBFs seem to be driven by trading activities similar to those performed by convertible arbitrageurs, such as the selection of undervalued convertibles (long part) or even, for some funds, convertible-arbitrage strategies using short stock positions (short part).

In the multivariate cross-sectional regressions (Table XV), we analyze whether the abnormal performance of CBFs is related to specific fund characteristics. Remarkably, once the SD-factor is taken into account, no significant relation between CBF abnormal returns and holding-based variables can be found. Thus, most likely, the previously obtained positive relation between fund performance and the difference in percentage holdings invested in convertible bonds and stocks is, to a large extent, attributable to the investment opportunities in the convertible-bond market, as proxied by the supply and demand factor SD. 


\section{Table XV \\ Multivariate Panel Regression Evidence: Supply and Demand Factor}

This table reports the coefficients of the monthly panel and multivariate cross-sectional regression of the general form: PERF $_{\mathrm{i}, \mathrm{t}}=\mathrm{c}+\chi_{1} \mathrm{HV}_{\mathrm{i}, \mathrm{t}-1}+\chi_{2} \mathrm{LNTNA}_{\mathrm{i}, \mathrm{t}-1}+\chi_{3} \mathrm{ACTIVE}_{\mathrm{i}, \mathrm{t}-1}+\chi_{4} \mathrm{NMG}_{\mathrm{i}, \mathrm{t}-1}+\chi_{5} \mathrm{EXP}_{\mathrm{i}, \mathrm{t}-\mathrm{l}}+\varepsilon_{\mathrm{i}, \mathrm{t}}$ where HV stands for the holding-based variables: CB-S, $\mathrm{S}, \mathrm{B}, \mathrm{CB}$ and $\mathrm{B}-\mathrm{S}$. The dependent variable, PERF, measures the monthly performance (abnormal return) using two different performance models (Panel A and Panel B) based on 36 months of lagged data to determine the betas in the performance models The abnormal returns are calculated as follows: $\mathrm{PERF}_{\mathrm{i}, \mathrm{t}}=\mathrm{FUND}_{\mathrm{i}, \mathrm{t}}-\Sigma_{\mathrm{k}} \beta_{\mathrm{i}, \mathrm{t}-1}^{\mathrm{k}} \mathrm{F}_{\mathrm{t}}^{\mathrm{k}}$ and $\mathrm{F}_{\mathrm{t}}^{\mathrm{k}}$ are the factors in the performance model. The holding-based variables are the asset compositions in percentages invested in convertible bonds (CB), stocks (S), bonds inclusive convertible bonds (B), convertible bonds minus stocks (CB-S) and bonds inclusive convertible bonds minus stocks (B-S), respectively. We denote the natural logarithm of total net assets by LNTNA, the new money growth per month by NMG and the expense ration by EXP. The variable ACTIVE is a dummy variable and is one if the convertible bond fund is active and zero otherwise. Mitigating potential endogeneity problems, we lag all explanatory variables by one month. The sample includes convertible-bond funds from the CRSP Survivor-Bias Free US Mutual Fund Database and spans the period from 1995 to 2004 including the data used for calculating the abnormal returns. Panel-corrected standard errors (PCSE) are reported in parenthesis.

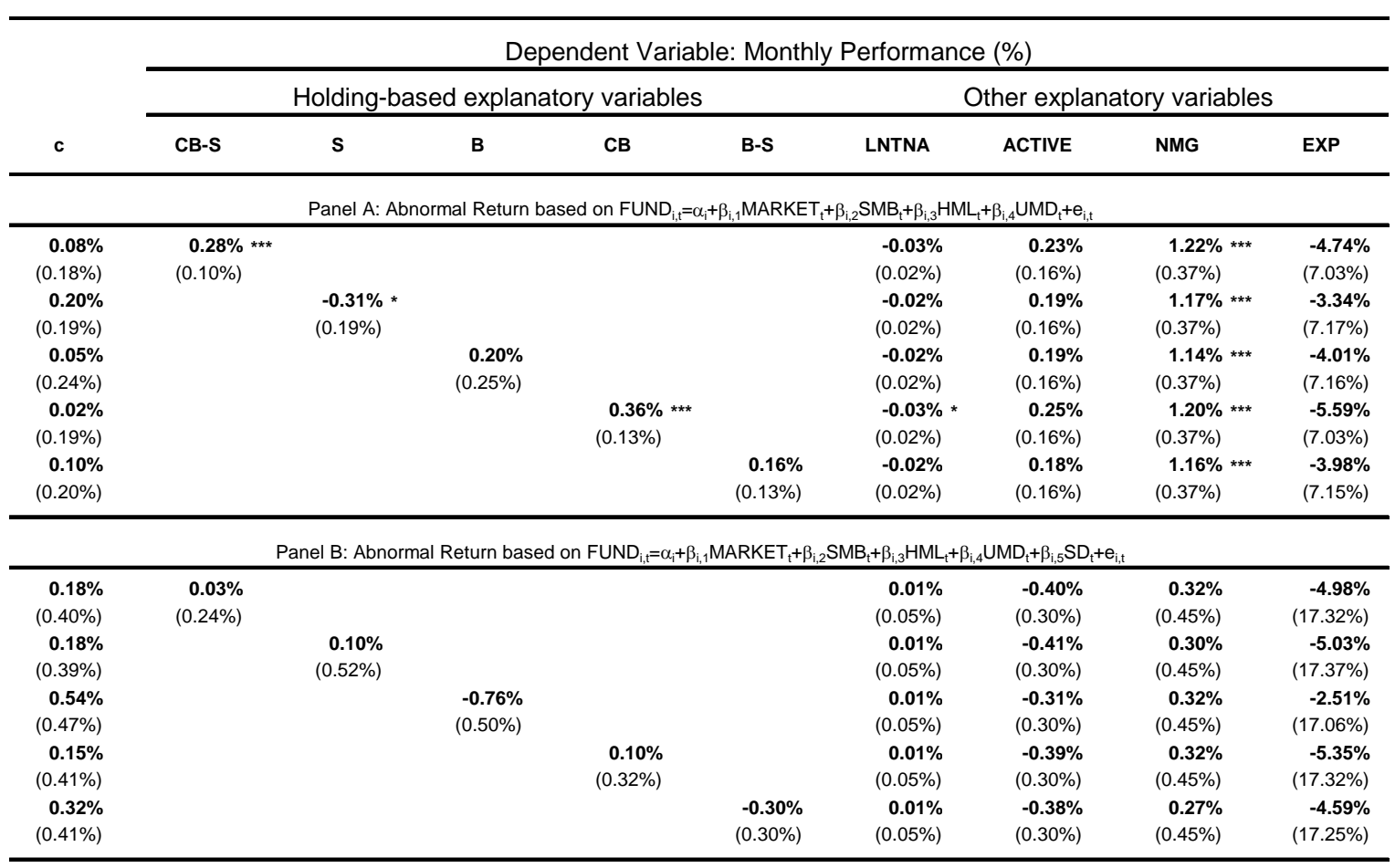




\subsection{Timing}

In this subsection, we include timing factors in the models to test whether CBF managers have timing skills. We analyze timing in the following four markets: stock market $(\mathrm{MARKET})^{2}$, bond market $(\mathrm{BOND})^{2}$, convertible bond market $(\mathrm{CBI})^{2}$, and convertible arbitrage $(\mathrm{CBAI})^{2}$. The results in Table XVI indicate that CBFs have timing skills both in the convertible bond market and convertible arbitrage. In times when convertible bonds and convertible arbitrage yields positive returns, CBF managers more actively pursue such investment strategies. Interestingly, while the loadings for the factors $(\mathrm{CBI})^{2}$ and $(\mathrm{CBAI})^{2}$ are always positive at the one percent significantly level, the loadings related to stock and bond market timing are not. It has to be noted that the above findings hold for a large set of models, in particular also models that already include CBI and CBAI as explanatory variables. Thus, the results are not driven by the convex payoff structure of convertible bonds.

We investigate whether $(\mathrm{CBI})^{2}$ and $(\mathrm{CBAI})^{2}$ have to be considered as two well distinct timing skills by considering, as in Section 5.2, two sub-periods: pre- and post LTCM crisis. Funds are found to be successfully engaged in convertible bond timing (CBI) ${ }^{2}$ in both periods (pre- and post LTCM crisis), while timing skills in the convertible arbitrage market can only be detected after the LTCM crisis. This suggests that $(\mathrm{CBI})^{2}$ and $(\mathrm{CBAI})^{2}$ indeed capture separate timing skills, the latter skill being present only in the second part of the sample. 
Finally, Table XVII shows that the previously found positive cross-sectional relationship between the performance of CBFs' and the holding variable CB-S (Panel A) still holds when considering in Panel B the timing factor $(\mathrm{CBI})^{2}$ and in Panel $\mathrm{C}$ the factor $(\mathrm{CBAI})^{2}$. 
Table XVI

\section{Models including a Timing Factor}

This table reports the coefficients of the panel regression of the general form: $\mathrm{FUND}_{\mathrm{i}, \mathrm{t}}=\alpha_{\mathrm{i}}+\Sigma_{\mathrm{k}} \beta_{\mathrm{i}}^{\mathrm{k}} \mathrm{F}_{\mathrm{t}}^{\mathrm{k}}+\mathrm{e}_{\mathrm{i}, \mathrm{t}}$ and $\mathrm{F}_{\mathrm{t}}^{\mathrm{k}}$ are the factors in the performance model and $\mathrm{FUND}$ are the monthly excess-returns of convertible bond fund $i$. The factors of the Carhart (1997) four-factor model are defined as follows: MARKET is the value-weight return on all NYSE, AMEX, and NASDAQ stocks (from CRSP) minus the one-month Treasury bill rate (from Ibbotson Associates), SMB (Small Minus Big) is the average return on three small

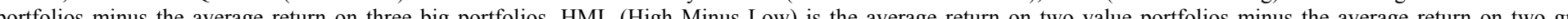
( pots (1997) factors are from the Kenneth R. Fuch data library on his webpage. SD is the supply demand factor. CBAI is the return on the CSFB/Tremont Convertible Arbitrage Index. CB is the return on the Merill Lynch All US Convertible Bond Index. . All factor are not ongonalized. All data are provided by Datastream except for the Carhart (1997) factors. Measures are the arite Fund Database and spans the period from 1994 to 2004

\begin{tabular}{|c|c|c|c|c|c|c|c|c|c|c|c|c|c|}
\hline ALPHA & MARKET & SMB & HML & UMD & TERM & DEFT & CBI & CBAI & (MARKET) $^{2}$ & $(B O N D)^{2}$ & $(\mathrm{CBI})^{2}$ & $(\mathrm{CBAI})^{2}$ & $\operatorname{Adj} R^{2}$ \\
\hline-0.001 & 0.672 *** & $0.135 * * *$ & 0.069 ** & $0.091 * \star \star *$ & & & & & -0.264 & & & & 0.69 \\
\hline-0.001 & $0.680 * * *$ & $0.139 * * *$ & 0.071 ** & $0.092 * \star \star *$ & & & & & & -0.544 & & & 0.69 \\
\hline$-0.003 * * *$ & $0.682 * * *$ & $0.140 * * *$ & $0.075 * \star *$ & $0.083 * * *$ & & & & & & & $1.585 * \star \star$ & & 0.69 \\
\hline-0.003 ** & $0.703 * * *$ & 0.136 *** & 0.056 * & $0.111 * \star \star$ & & & & & & & & $6.715^{* *}$ & 0.69 \\
\hline-0.004 *** & 0.570 *** & $0.100 * * \star$ & 0.040 & $0.095^{\star * \star}$ & & & 0.174 *** & $0.341 * * *$ & -0.208 & & & & 0.72 \\
\hline$-0.005 * \star *$ & 0.576 *** & $0.100 * * *$ & 0.040 & $0.097 * * *$ & & & 0.171 *** & 0.356 *** & & 1.861 & & & 0.72 \\
\hline$-0.006 * \star \star *$ & $0.574 * * *$ & $0.107 * * *$ & 0.043 & $0.082 * * *$ & & & $0.165 * * *$ & $0.354 * * *$ & & & $1.569 * \star *$ & & 0.73 \\
\hline$-0.006 * * *$ & 0.588 *** & $0.121 * * *$ & 0.032 & $0.105^{* * *}$ & & & $0.153^{* * *}$ & $0.381 * * *$ & & & & 7.356 *** & 0.73 \\
\hline$-0.003 * * *$ & $0.562 * \star \star$ & $0.094 * * *$ & 0.029 & $0.100 * \star \star$ & 0.055 & 0.117 & 0.165 *** & 0.324 *** & -0.161 & & & & 0.72 \\
\hline$-0.005 * * *$ & $0.565 * \star \star$ & $0.094 * * *$ & 0.029 & $0.103 * \star \star$ & $0.085 * *$ & 0.131 & $0.163 * * *$ & 0.338 *** & & 4.272 & & & 0.72 \\
\hline$-0.006 * * *$ & $0.562 * \star *$ & $0.099 * \star \star$ & 0.031 & $0.089 * \star \star$ & 0.065 * & 0.144 * & $0.155 * * *$ & $0.331 * \star *$ & & & $1.606 * \star *$ & & 0.74 \\
\hline$-0.006 * \star *$ & 0.576 *** & 0.114 *** & 0.017 & 0.114 *** & 0.065 * & 0.164 * & $0.140 * \star *$ & $0.360 * * *$ & & & & $8.185 * * *$ & 0.73 \\
\hline
\end{tabular}




\section{Table XVII \\ Cross-Sectional Dependence and Timing Factors}

This table reports the coefficients of the monthly panel and multivariate cross-sectional regression of the general form: PERF $_{\mathrm{i}, \mathrm{t}}=\mathrm{c}+\chi_{1}(\mathrm{CB}-\mathrm{S})_{\mathrm{i}, \mathrm{t}-1}+\chi_{2} \mathrm{LNTNA}_{\mathrm{i}, \mathrm{t}-1}+\chi_{3} \mathrm{ACTIVE}_{\mathrm{i}, \mathrm{t}-1}+\chi_{4} \mathrm{NMG}_{\mathrm{i}, \mathrm{t}-1}+\chi_{5} \mathrm{EXP}_{\mathrm{i}, \mathrm{t}-1-1}+\varepsilon_{\mathrm{i}, \mathrm{t}}$. The dependent variable, PERF, measures the monthly performance (abnormal return) using three different performance models (Panel AC) based on 36 months of lagged data to determine the betas in the performance models. The abnormal returns are calculated as follows: $\mathrm{PERF}_{\mathrm{i}, \mathrm{t}}=\mathrm{FUND}_{\mathrm{i}, \mathrm{t}} \Sigma_{\mathrm{k}} \beta_{\mathrm{i}, \mathrm{t}-1}^{\mathrm{k}} \mathrm{F}_{\mathrm{t}}^{\mathrm{k}}$ and $\mathrm{F}_{\mathrm{t}}^{\mathrm{k}}$ are the factors in the performance model. The holding-based variable is the asset compositions in percentages invested convertible bonds minus stocks (CB-S). We denote the natural logarithm of total net assets by LNTNA, the new money growth per month by NMG and the expense ration by EXP. The variable ACTIVE is a dummy variable and is one if the convertible bond fund is active and zero otherwise. Mitigating potential endogeneity problems, we lag all explanatory variables by one month. The sample includes convertible-bond funds from the CRSP Survivor-Bias Free US Mutual Fund Database and spans the period from 1995 to 2004 - including the data used for calculating the abnormal returns. Panel-corrected standard errors (PCSE) are reported in parenthesis.

\begin{tabular}{|c|c|c|c|c|c|}
\hline \multirow[b]{3}{*}{ c } & \multicolumn{5}{|c|}{ Dependent Variable: Monthly Performance (\%) } \\
\hline & \multicolumn{5}{|c|}{ explanatory variables } \\
\hline & CB-S & LNTNA & ACTIVE & NMG & EXP \\
\hline \multicolumn{6}{|c|}{ Panel A: Abnormal Return based on $R_{i, t}-R_{F, t}=\alpha_{i}+\beta_{i, 1}\left(R_{M, t}-R_{F, t}\right)+\beta_{i, 2} S M B_{t}+\beta_{i, 3} H M L_{t}+\beta_{i, 4} U M D_{t}+e_{i, t}$} \\
\hline $0.08 \%$ & $0.28 \% * * *$ & $-0.03 \%$ & $0.23 \%$ & $1.22 \% * \star \star$ & $-4.74 \%$ \\
\hline$(0.18 \%)$ & $(0.10 \%)$ & $(0.02 \%)$ & $(0.16 \%)$ & $(0.37 \%)$ & $(7.03 \%)$ \\
\hline \multicolumn{6}{|c|}{ Panel B: Abnormal Return based on $R_{i, t}-R_{F, t}=\alpha_{i}+\beta_{i, 1}\left(R_{M, t}-R_{F, t}\right)+\beta_{i, 2} S M B_{t}+\beta_{i, 3} H M L_{t}+\beta_{i, 4} U M D_{t}+\beta_{i, 5}(C B I)^{2}{ }_{t}+e_{i, t}$} \\
\hline$-0.33 \%$ * & $0.28 \% * * *$ & $-0.02 \%$ & $0.54 \%$ *** & $0.94 \% * \star \star$ & $-9.22 \%$ \\
\hline$(0.17 \%)$ & $(0.10 \%)$ & $(0.02 \%)$ & $(0.15 \%)$ & $(0.36 \%)$ & (6.13\%) \\
\hline \multicolumn{6}{|c|}{ Panel C: Abnormal Return based on $R_{i, t}-R_{F, t}=\alpha_{i}+\beta_{i, 1}\left(R_{M, t}-R_{F, t}\right)+\beta_{i, 2} S M B_{t}+\beta_{i, 3} H M L_{t}+\beta_{i, 4} U M M D_{t}+\beta_{i, 5}(C B A I)_{t}^{2}+e_{i, t}$} \\
\hline$-0.25 \%$ & $0.50 \% * \star *$ & $-0.02 \%$ & $0.26 \%$ & $0.94 \%$ ** & $-11.30 \%$ \\
\hline$(0.26 \%)$ & $(0.13 \%)$ & $(0.02 \%)$ & $(0.22 \%)$ & $(0.38 \%)$ & $(9.50 \%)$ \\
\hline
\end{tabular}

*** $1 \%$ significance, ${ }^{\star *} 5 \%$ significance, ${ }^{*} 10 \%$ significance 


\section{Discussion of CBF Performance}

This section builds on the results of the previous sections and explicitly addresses the magnitude of funds' performance. First, we compute Jensen's alphas for models including stock, bond, and option factors. As reported in Table XVIII, Panel A, the large majority of CBFs display non-significant alphas (83\%-93\%). The average alpha is moderately positive with values between $0.04 \%$ and $0.07 \%$ per month.

Second, we analyze alphas by including a convertible-arbitrage factor (CBAI) and obtain a slight increase of average alphas and the number of significantly positive alphas (Table XVIII, Panel B). Thus, convertible arbitrage has, if any, a negative impact on the returns of CBFs (including CBAI increases the alphas on average, and demonstrates the negative impact of arbitrage related activities on CBF absolute returns).

Third, we include the SD factor capturing investment opportunities in the convertible-bond (Table XVIII, Panel C). Interestingly, average alphas become negative (-0.56\%) and the number of significantly negative alphas increases to $41 \%$. We interpret the dependence of CBF returns on the supply and demand factor SD as an indicator for changing convertiblearbitrage activity of CBFs. In times of ample convertible-bond supply, CBFs tend to implement investment strategies related to convertible arbitrage, which increases, in this

case, fund returns. This market-timing hypothesis is confirmed in Section 5.3. The second row in Panel C of Table XVIII shows that if the CBAI factor is added to the SD factor the average alphas increase. This results confirms that SD lowers the alphas and CBAI increases the alphas on average. 
As reported in Table XVIII, Panel D, average alphas are significantly negative when convertible-bond timing or convertible-arbitrage timing is explicitly considered by $(\mathrm{CBI})^{2}$ and $(\mathrm{CBAI})^{2}$. Thus, including $\mathrm{SD},(\mathrm{CBI})^{2}$ or $(\mathrm{CBAI})^{2}$ lowers the alphas on average, and demonstrates the positive impact of timing on $\mathrm{CBF}$ absolute returns. This is even more surprising when recalling that the non-linear factor, $(\text { MARKET) })^{2}$, capturing conventional stock market timing, was not statistically significant in previous analyses.

Summing up, when compared to passive investment strategies, CBFs deliver a performance similar to those strategies. This result is not very exciting, but the way how $\mathrm{CBF}$ obtain it is more interesting. First, CBFs seem to implement dynamic trading strategies related to convertible arbitrage but, overall, they are less successful than convertible-arbitrage hedge funds. Second, CBFs seem to increase their convertiblearbitrage activities in phases when this strategy performs well, i.e., when investment opportunities in the convertible-bond market are good. Third, CBFs seem to have convertible bond timing skills. These two successful timing activities compensate the weak selection skills of CBF portfolio managers in the stock, bond, and convertible-bond market. 


\section{Table XVIII}

\section{Analysis of the Alphas}

This table reports the percentage of statistically significant alphas (PERF) and the mean (per month) of the alphas (PERF) for all convertible bond funds in our sample determined with the different factor models introduced before. Panel A shows the percentage of significances for the standard models, Panel B for the extended models (with a convertible arbitrage factor), and Panel C for a model with a supply and demand (SD) factor. The sample includes 114 convertible bond funds from the CRSP Survivor-Bias Free US Mutual Fund Database and spans the period from 1985 to 2004

\begin{tabular}{|c|c|c|c|c|}
\hline Models & $\begin{array}{l}\text { Percentage of } \\
\text { significantly } \\
\text { negative alphas } \\
\left(P E R F_{i, t}\right)\end{array}$ & $\begin{array}{l}\text { Percentage of } \\
\text { non-significant } \\
\text { alphas }\left(P E R F_{i, t}\right)\end{array}$ & $\begin{array}{l}\text { Percentage of } \\
\text { significantly } \\
\text { positive alphas } \\
\left(P E R F_{i, t}\right)\end{array}$ & $\begin{array}{l}\text { Mean of alphas } \\
\quad\left(P E R F_{i, t}\right)\end{array}$ \\
\hline \multicolumn{5}{|c|}{ Panel A } \\
\hline CARHART $\left(R_{M}-R_{F}, S M B ~ H M L\right.$, and UMD) & $9 \%$ & $89 \%$ & $2 \%$ & $0.07 \%$ \\
\hline CARHART + TERM + DEFT & $5 \%$ & $93 \%$ & $3 \%$ & $0.06 \%$ \\
\hline CARHART + HY & $5 \%$ & $88 \%$ & $7 \%$ & $0.07 \%$ \\
\hline CARHART + CBI & $9 \%$ & $83 \%$ & $9 \%$ & $0.04 \%$ \\
\hline CARHART + TERM + DEFT + CBI & $6 \%$ & $89 \%$ & $5 \%$ & $0.06 \%$ \\
\hline CARHART + HY + CBI & $10 \%$ & $83 \%$ & $8 \%$ & $0.07 \%$ \\
\hline \multicolumn{5}{|c|}{ Panel B } \\
\hline CARHART + CBAI & $1 \%$ & $85 \%$ & $13 \%$ & $0.10 \%$ \\
\hline CARHART + TERM + DEFT + CBAI & $1 \%$ & $86 \%$ & $13 \%$ & $0.08 \%$ \\
\hline CARHART + HY + CBAI & $3 \%$ & $81 \%$ & $16 \%$ & $0.13 \%$ \\
\hline CARHART + CBI + CBAI & $1 \%$ & $88 \%$ & $11 \%$ & $0.05 \%$ \\
\hline CARHART + TERM + DEFT + CBI + CBAI & $5 \%$ & $85 \%$ & $10 \%$ & $0.01 \%$ \\
\hline $\mathrm{CARHART}+\mathrm{HY}+\mathrm{CBI}+\mathrm{CBAI}$ & $6 \%$ & $85 \%$ & $9 \%$ & $0.09 \%$ \\
\hline \multicolumn{5}{|c|}{ Panel C } \\
\hline CARHART + SD & $41 \%$ & $48 \%$ & $11 \%$ & $-0.56 \%$ \\
\hline CARHART + SD + CBAI & $21 \%$ & $60 \%$ & $19 \%$ & $-0.12 \%$ \\
\hline \multicolumn{5}{|c|}{ Panel D } \\
\hline $\mathrm{CARHART}+(\mathrm{CBI})^{2}$ & $20 \%$ & $78 \%$ & $2 \%$ & $-0.14 \%$ \\
\hline CARHART + $(\mathrm{CBAI})^{2}$ & $22 \%$ & $78 \%$ & $0 \%$ & $-0.31 \%$ \\
\hline $\mathrm{CARHART}+\mathrm{CBI}+\mathrm{CBAI}+(\mathrm{CBI})^{2}$ & $53 \%$ & $48 \%$ & $0 \%$ & $-0.53 \%$ \\
\hline $\mathrm{CARHART}+\mathrm{CBI}+\mathrm{CBAI}+(\mathrm{CBAI})^{2}$ & $49 \%$ & $51 \%$ & $0 \%$ & $-0.45 \%$ \\
\hline
\end{tabular}




\section{Conclusions}

This paper presents the first empirical study on convertible-bond funds (CBFs). We examine systematic factors that affect CBF returns using a complete and survivorship-biasfree sample of US convertible-bond funds in the period from 1985 to 2004 . Risk factors can be divided into four categories: (i) stock factors as used in Carhart (1997); (ii) bond factors related to the term structure and credit risk; (iii) factors reflecting the option-like nature of convertible bonds, such as stock-market volatility and non-linear market factors; and (iv) fund factors related to CBF trading activity.

Carhart (1997) factors capture a significant portion of CBF returns and should therefore be included in the data-generating process. Default risk tends to be explained equally well by a high-yield index factor and by the return difference between a long-term corporate bond index and a long-term government bond index. The hybrid character of convertible bonds is best captured by a convertible-bond index. Neither an implied volatility index nor other factors related to the non-linear payoffs of convertible bonds seem to be appropriate as explanatory variables.

We show that for a set of plausible models there is a positive relationship between the abnormal performance of convertible-bond funds and the difference in the funds' holdings of convertible bonds and stocks. We argue that this relationship can be explained by trading activities related to convertible arbitrage. Following this line of reasoning, we extend all models by a convertible-arbitrage factor and a supply-demand factor of the 
convertible-bond market proxying for investment opportunities in this market. With this set of models, the cross-sectional relationship between fund performance and portfolio holdings disappears. The results are found to be robust with respect to alternative risk adjustments and time periods.

Building on the above insights, we assess the performance of convertible-bond funds and draw the following conclusions. First, CBF returns often do not significantly differ from a normal distribution and thus do not provide an appreciable protection against adverse movements in the stock market. Second, CBFs seem to implement dynamic trading strategies related to convertible arbitrage but, overall, they are less successful than convertible-arbitrage hedge funds. Third, CBFs seem to increase their convertible-arbitrage activities in phases when this strategy performs well, i.e., when investment opportunities in the convertible-bond market are good (convertible-arbitrage timing). Further timing skills exist with respect to the convertible-bond market but not the stock market. Finally, successful timing compensates but does not overcompensate the management fees and the weak selection skills of CBF portfolio managers in the stock, bond, and convertible-bond market. 


\section{References}

Agarwal, V. and Naik, N.Y., 2004, Risks and Portfolio Decisions Involving Hedge Funds, Review of Financial Studies 17, 63-98

Agarwal, V., W.H. Fung, Y.C. Loon and N.Y. Naik, 2006, Risk and Return in Convertible Arbitrage: Evidence from the Convertible Bond Market, Working Paper Georgia State University and London Business School.

Ammann, M., Kind A., and C. Wilde, 2003, Are convertible bonds underpriced? An analysis of the French market, Journal of Banking and Finance 27 (4), 635-653

Ammann, M., Kind A., and C. Wilde, 2007, Simulation-Based Pricing of Convertible Bonds, Journal of Empirical Finance (forthcoming)

Ang, A., and J. Chen, 2005, CAPM over the long run: 1926-2001, NBER Working Paper 1190

Arshanapalli B., F. Fabozzi, L. N. Switzer and G. Gosselin, 2004, New Evidence on the market impact of convertible bond issues in the US, Working Paper, Concordia University, Montreal

Beck, N., and J. N. Katz, 1995, What to do (and not to do) with time-series cross-section data, American Political Science Review 89(3), 634-647

Berk, J., R. C. Green, and V. Naik, 1999, Optimal investment, growth options, and security returns, Journal of Finance, October, 1553-1607

Blake, C.R., Elton E.J., and M.J. Gruber, 1993, The Performance of Bond Mutual Funds, Journal of Business 66 (3), 371-403

Burmeister, E. and K. Wall, 1986, The arbitrage pricing theory and macroeconomic factor measures, The Financial Review 21, 1-20

Carayannopoulos, P., and M. Kalimipalli, 2003, Convertible bond prices and inherent biases, Journal of Fixed Income 13, 64-73 
Carhart, M., 1997, On Persistence in Mutual Fund Performance, Journal of Finance 52 (1), $57-82$

Chen, N., Roll, R., and S. A. Ross, 1986, Economic forces and the stock market, Journal of Business 59, 383-403

Detzler, M.L., 1999, The Performance of global bind mutual funds, Journal of Banking and Finance 23, 1195-1217

Elton, E.J., M.J. Gruber and C.R. Blake, 1995, Fundamental Economic Variables, Expected Returns, and Bond Fund Performance, Journal of Finance 50 (4), 1229-1256

Elton, E.J., M.J. Gruber and C.R. Blake, 1999, Common Factors in Active and Passive Portfolios, European Finance Review 3, 53-78

Elton, E.J., M.J. Gruber and C.R. Blake, 2003, Incentive Fees and Mutual Funds, Journal of Finance 58 (2), 779-804

Evans, N., 2002, Is the game over for hedge funds?, Euromoney.

Fama, E.F., and K.R. French, 1989, Business Conditions and Expected Returns on Stocks and Bonds, Journal of Financial Economics 25, 23-49

Fama, E.F., and K.R. French, 1992, The cross-section of expected stock returns, Journal of Finance 47, 427-465

Fama, E.F., and K.R. French, 1993, Common risk factors in the return on stocks and bonds, Journal of Financial Economics 33, 3-56

Ferson, W., and R. Schadt, 1996, Measuring fund strategy and performance in changing economic conditions, Journal of Finance 51 (2), 425-462

Fung, W., and D. A. Hsieh, 2004a, Hedge Fund Benchmarks: A Risk Based Approach, Financial Analysts Journal, 60, 65-80

Fung, W., Hsieh, D.A., Naik, N.Y., and T. Ramadorai, 2005, Hedge Funds: 
Performance, Risk, and Capital Formation, Working Paper, Duke University, London Business School and University of Oxford

Lummer, S.L. and M.W. Riepe, 1993, Convertible bonds as an asset class; 1957-1992, Journal of Fixed Income, 3(2), 1993

Harvey, C.R., 2001, The specification of conditional expectations. Journal of Empirical Finance 8, 573-638

Henriksson, R., and R. Merton, 1981, On market timing and investment performance, Journal of Business 54, 513-33

Jagannathan, R., and Z. Wang, 1996, The conditional CAPM and the cross-section of expected returns, Journal of Finance 51, 3-53

Kacperczyk, M., Sialm C. and L. Zheng, 2005, On the Industry Concentration of Actively Managed Equity Mutual Funds, Journal of Finance 60(4), 1984-2011

King, R., 1986, Convertible bond valuation: An empirical test, Journal of Financial Research 9 (1), 53-69

Lettau, M., and S. Ludwigson, 2001, Resurrecting the (C)CAPM: a cross-sectional test whet rink premia are time-varying, Journal of Political Economy 109, 1238-1287

Lewellen, J. and S. Nagel, 2003, The conditional CAPM does not explain asset-pricing anomalies, Manuscript, MIT

Merton, R. C., 1973, An intertemporal capital asset pricing model, Econometrica 41, 867887

Newey, W.K., and K.D. West, 1987, A simple positive definite Heteroskedasticity and Autocorrelation consistent Covariance Matrix, Econometrica 55, 703-708

Sirri, E., and P. Tufano, 1992, Buying and selling mutual funds: Flows, performance, fees and service, Working Paper, Harvard University.

Treynor, J., and K. Mazuy, 1966, Can mutual funds outguess the market? Harvard Business Review 44,131-36 
Treynor, J. L., and F. Black, 1973, How to use security analysis to improve portfolio selection, Journal of Business 46, 66-86 


\section{Appendix: Risk Factors and Explanatory Variables}

Table A, Panel A presents the time-series variables used as factors of the data-generating processes employed in this study. Table A, Panel B refers to the cross-sectional variables. Monthly time-series are obtained from Datastream and the Kenneth R. French Data Library $^{18}$. The cross-sectional explanatory variables are from CRSP. Table B reports the correlations among the cross-sectional (Panel A) and time-series (Panel B) explanatory variables. In order to cope with the problem of multicollinearity, some variables are orthogonalized before being used as regressors.

\footnotetext{
${ }^{18}$ Kenneth French's Web site: http://mba.tuck.dartmouth.edu/pages/faculty/ken.french/data_library.html
} 


\section{Table A}

\section{Description of Explanatory Variables}

This table describes the explanatory variables in this study (Panel A time-series variables and Panel B cross-sectional variables). The monthly time-series data are provided by Datastream or the Kenneth R. French Data Library. The cross-sectional explanatory variables are provided by the CRSP Survivorship Bias Free US Mutual Fund Database. Fund characteristics (EXP, CB, S, and B) are provided yearly or even more often, all other variables are provided monthly.

\begin{tabular}{|c|c|c|c|c|}
\hline \multicolumn{5}{|c|}{ Panel A: Time-Series Input Parameters } \\
\hline Parameter & Definition & Datasource & Start Date & End Date \\
\hline MARKET & $\begin{array}{l}\text { Value-weight return on all NYSE, AMEX, and NASDAQ stocks (from CRSP) minus the one-month Treasury bill rate (from } \\
\text { Ibbotson Associates) }\end{array}$ & Kenneth R. French - Data Library & 1985 & 2004 \\
\hline SMB & SMB (Small Minus Big) is the average return on three small portfolios minus the average return on three big portfolios & Kenneth R. French - Data Library & 1985 & 2004 \\
\hline HML & HML (High Minus Low) is the average return on two value portfolios minus the average return on two growth portfolios & Kenneth R. French - Data Library & 1985 & 2004 \\
\hline UMD & $\begin{array}{l}\text { UMD (Up Minus Down) is the average return on two high prior return portfolios minus the average return on two low prior } \\
\text { return portfolios }\end{array}$ & Kenneth R. French - Data Library & 1985 & 2004 \\
\hline TERM & Return of the Lehman US Government Long Bond Index minus the one-month Treasury bill rate (from Ibbotson Associates) & $\begin{array}{l}\text { Datastream/ } \\
\text { Kenneth R. French - Data Library }\end{array}$ & 1985 & 2004 \\
\hline DEFT & Return on the Lehman US Corporate Long Bond Index minus the return of the Lehman US Government Long Bond Index & Datastream & 1985 & 2004 \\
\hline BOND & $\begin{array}{l}\text { Return on the Lehman US aggregated Government/Credit Bond Index minus one-month Treasury bill rate (from Ibbotson } \\
\text { Associates) }\end{array}$ & $\begin{array}{l}\text { Datastream/ } \\
\text { Kenneth R. French - Data Library }\end{array}$ & 1985 & 2004 \\
\hline HY & Return on the Merrill Lynch US High Yield Index & Datastream & 1985 & 2004 \\
\hline VOLA & Return on the CBOE Volatility VXO Index & Datastream & 1986 & 2004 \\
\hline $\max (0$, MARKET-BOND) & $\begin{array}{l}\text { The maximum of zero and the value-weight return on all NYSE, AMEX, and NASDAQ stocks (from CRSP) minus the return on } \\
\text { the Lehman US aggregated Government/Credit Bond IIdex }\end{array}$ & $\begin{array}{l}\text { Kenneth R. French - Data Library/ } \\
\text { Datastream }\end{array}$ & 1985 & 2004 \\
\hline$(\text { MARKET) })^{2}$ & $\begin{array}{l}\text { Value-weight return on all NYSE, AMEX, and NASDAQ stocks (from CRSP) minus the one-month Treasury bill rate (from } \\
\text { Ibbotson Associates) squared }\end{array}$ & Kenneth R. French - Data Library & 1985 & 2004 \\
\hline CBI & Return on the Merrill Lynch All US Convertible Bond Index & Datastream & 1988 & 2004 \\
\hline CBAI & Return on the CSFB/Tremont Convertible Arbitrage Index & Datastream & 1994 & 2004 \\
\hline \multicolumn{5}{|c|}{ Panel B: Cross-Sectional Input Parameters } \\
\hline FUND & Monthly CBF excess-return & CRSP & 1985 & 2004 \\
\hline TNA & $\begin{array}{l}\text { The Total Net Assets (TNA) is the closing market value of securities owned, plus all assets, minus all liabilities (TNAs are } \\
\text { reported in millions of dollars) }\end{array}$ & CRSP & 1985 & 2004 \\
\hline EXP & $\begin{array}{l}\text { Expense Ratio is the percentage of the total investment that shareholders } \\
\text { pay for the mutual fund's operating expenses }\end{array}$ & CRSP & 1987 & 2004 \\
\hline СВ & The Percentage Invested in Convertible Bonds & CRSP & 1995 & 2004 \\
\hline$s$ & The Percentage Invested in Common Stocks & CRSP & 1995 & 2004 \\
\hline B & $\begin{array}{l}\text { The Percentage Invested in Bonds is the percentage of the } \\
\text { fund invested in preferred, corporate, municipal, government, and convertible bonds }\end{array}$ & CRSP & 1995 & 2004 \\
\hline
\end{tabular}




\section{Table B}

\section{Correlation Matrices}

This table reports the correlations for the cross-sectional (Panel A) and time-series (Panel B) explanatory variables. In the crosssectional analysis, some variables have been tested separately due to their multicollinearity. In the time-series analysis, some variables have been orthogonalized due to their high correlations. The holding-based variables are the asset compositions in percentages invested in convertible bonds (CB), stocks (S), bonds inclusive convertible bonds (B), convertible bonds minus stocks (CB-S) and bonds inclusive convertible bonds minus stocks (B-S), respectively. We denote the natural logarithm of total net assets by LNTNA, the new money growth per month by NMG and the expense ration by EXP. The variable ACTIVE is a dummy variable that is one if the convertible bond fund is active and zero otherwise. All holding-based variables are provided by CRSP. MARKET is the value-weighted return on all NYSE, AMEX, and NASDAQ stocks (from CRSP) minus the one-month Treasury bill rate (from Ibbotson Associates), SMB (Small Minus Big) is the average return on three small portfolios minus the average return on three big portfolios, HML (High Minus Low) is the average return on two value portfolios minus the average return on two growth portfolios, UMD (Up Minus Down) is the average return on two high prior return portfolios minus the average return on two low prior return portfolios. TERM is the return of the Lehman US Government Long Bond Index minus the one-month Treasury bill rate. DEFT is the return on the Lehman US Corporate Long Bond Index minus the return of the Lehman US Government Long Bond Index. BOND is the return on the Lehman US aggregated Government/Credit Bond Index minus one-month Treasury bill rate. HY is the return on the Merrill Lynch US High Yield Index. VOLA is the return on the CBOE Volatility VXO Index. max(0,MARKET-BOND) is the maximum of zero and the value-weighted return on all NYSE, AMEX, and NASDAQ stocks minus the return on the Lehman US aggregated Government/Credit Bond Index. (MARKET) ${ }^{2}$ is the valueweighted return on all NYSE, AMEX, and NASDAQ stocks minus the one-month Treasury bill rate squared. CBI is the return on the Merrill Lynch All US Convertible Bond Index. CBAI is the return on the CSFB/Tremont Convertible Arbitrage Index. All time-series data are provided by Datastream except for the Carhart (1997) factors that are from the Kenneth R. French data library on his webpage.

\begin{tabular}{|c|c|c|c|c|c|c|c|c|c|c|c|c|c|}
\hline \multicolumn{14}{|c|}{ Panel A: Correlation-matrix of cross-sectional data } \\
\hline & CB-S & $S$ & B & $\mathrm{CB}$ & B-S & LNTNA & ACTIVE & NMG & EXP & & & & \\
\hline CB-S & 1.00 & & & & & & & & & & & & \\
\hline $\mathrm{S}$ & -0.62 & 1.00 & & & & & & & & & & & \\
\hline B & 0.45 & -0.48 & 1.00 & & & & & & & & & & \\
\hline $\mathrm{CB}$ & 0.87 & -0.16 & 0.28 & 1.00 & & & & & & & & & \\
\hline B-S & 0.67 & -0.87 & 0.85 & 0.31 & 1.00 & & & & & & & & \\
\hline LNTNA & 0.03 & -0.05 & 0.01 & 0.00 & 0.01 & 1.00 & & & & & & & \\
\hline ACTIVE & -0.06 & -0.06 & 0.17 & -0.12 & 0.09 & 0.34 & 1.00 & & & & & & \\
\hline NMG & -0.07 & 0.06 & -0.02 & -0.05 & -0.04 & -0.06 & 0.01 & 1.00 & & & & & \\
\hline EXP & 0.03 & 0.04 & 0.07 & 0.07 & 0.03 & -0.25 & -0.01 & 0.08 & 1.00 & & & & \\
\hline \multicolumn{14}{|c|}{ Panel B: Correlation-matrix of time-series data } \\
\hline & MARKET & SMB & HML & UMD & TERM & DEFT & BOND & $\mathrm{HY}$ & VOLA & $\begin{array}{c}\max \\
(0, \text { MARKET- } \\
\text { BOND) }\end{array}$ & (MARKET) $^{2}$ & CBI & CBAI \\
\hline MARKET & 1.00 & & & & & & & & & & & & \\
\hline SMB & 0.12 & 1.00 & & & & & & & & & & & \\
\hline HML & -0.46 & -0.44 & 1.00 & & & & & & & & & & \\
\hline UMD & -0.09 & -0.20 & 0.13 & 1.00 & & & & & & & & & \\
\hline TERM & 0.11 & -0.21 & 0.08 & 0.11 & 1.00 & & & & & & & & \\
\hline DEFT & 0.17 & 0.28 & -0.11 & -0.26 & -0.65 & 1.00 & & & & & & & \\
\hline BOND & 0.12 & -0.21 & 0.09 & 0.09 & 0.96 & -0.52 & 1.00 & & & & & & \\
\hline HY & 0.57 & 0.24 & -0.19 & -0.24 & 0.21 & 0.28 & 0.26 & 1.00 & & & & & \\
\hline VOLA & -0.53 & -0.15 & 0.16 & 0.11 & 0.07 & -0.20 & 0.06 & -0.29 & 1.00 & & & & \\
\hline $\max (0, M A R K E T-B O N D)$ & 0.77 & 0.10 & -0.44 & -0.11 & -0.16 & 0.24 & -0.15 & 0.31 & -0.34 & 1.00 & & & \\
\hline$(\text { MARKET })^{2}$ & -0.34 & -0.20 & 0.09 & -0.07 & 0.16 & -0.19 & 0.15 & -0.27 & 0.42 & 0.15 & 1.00 & & \\
\hline $\mathrm{CBI}$ & 0.78 & 0.25 & -0.41 & -0.10 & 0.04 & 0.31 & 0.07 & 0.53 & -0.43 & 0.67 & -0.15 & 1.00 & \\
\hline CBAI & 0.14 & -0.03 & 0.13 & -0.04 & 0.10 & 0.20 & 0.12 & 0.35 & 0.07 & 0.04 & -0.19 & 0.29 & 1.00 \\
\hline
\end{tabular}

